\title{
CONCLUSIONS
}

\section{Comparing Dialects}

\section{a. Methods of Comparing Dialects}

To present an overall picture, a number of maps have been added in the appendix, which show a number of features of the dialects spoken in the area. To facilitate direct comparison, data used in maps in De Jong 2000, which cover the dialects of the northern Sinai littoral, have also been incorporated in these maps. A total of 13 maps have been added, which illustrate dialect features not used in De Jong 2000. In these additional maps dialect features are set as criteria for comparison to show differences between dialects spoken by tribes in the centre and south of Sinai; setting the same features as criteria for a comparison to be illustrated in maps would not have yielded very significant results in De Jong 2000, but these criteria do offer new perspectives when the entire area of Sinai is represented in a map.

In De Jong 2000 the northern Sinai littoral was shown to be an area of transition. This transition is between a largely Bedouin type of dialect (labelled group I), spoken by the majority of the Sinai tribes, and which has also been referred to as Negev Arabic (described in Blanc 1970) on the one hand, and the sedentary dialect of the eastern part of the Šarqiyyah province in the Nile Delta of Egypt.

Dialects in De Jong 2000 were compared using the 'step method'. Since the dialects form a geographical continuum, the linear nature of the comparison (i.e. only dialects bordering on each other were compared, mainly in a westeast (or vice versa) distribution) does not present a problem; after having made the comparison the continuum proved to be linguistic as well. ${ }^{1}$

However, since the dialects of central and southern Sinai do not form such a geographical continuum, a comparison using the step method becomes too two-dimensional, since more dimensions are needed to group dialects that do not lie along a more or less neat two-dimensional line.

\footnotetext{
${ }^{1}$ One of the reasons is that in the case of the Bedouin dialects of the northern Sinai littoral we saw - from east to west - a gradual disappearance of 'Bedouin' dialectal features, yielding to more sedentary features also found in the dialect of the eastern Nile Delta. The central and southern regions of Sinai do not form a continuum in the same or a comparable manner.
} 
For this reason the method of multi-dimensional scaling yields more reliable results for the grouping of dialects. All dialects (also the ones that do not geographically border on each other) are compared to each other on the basis of all features used as criteria for comparison. This means that also dialects that are far apart will receive a full comparison in this method, whereby the relative typological distance between these geographically far removed dialects can also be established. The advantage is clear: the fact that for instance TAN and TAS are clustered relatively near to each other may be interpreted as the result of a common history of these dialects; both are dialects of the same tribe (Tarāābin), although today these two varieties are spoken at locations hundreds of kilometres apart. ${ }^{2}$

Another advantage of the multi-dimensional scaling method is that parallel forms are more easily fitted into the comparison; every feature receives its own column in wich every dialect is marked for the presence or absence of this feature. When two parallel possibilities exist, their presence in the same dialect will be marked in the two columns created to record these features.

To give an example: When dialect A shows the use of interdentals, in dialect $\mathrm{B}$ interdentals have been replaced by stops, and in dialect $\mathrm{C}$ both forms with interdentals and forms with stops (which were originally interdentals) occur, this will be marked as follows:

E.g. in dialect A we heard: axad, țār, $\underline{\underline{d}} a r b$, In dialect B: $a x a d, t a \bar{r}, \underline{d a r b}$ and in dialect C: axad $\sim$ axad, tāa $r \sim t \bar{a} r, \underline{d}$ darb $\sim$ darb

$\begin{array}{lcc} & \underline{\mathrm{t}}, \underline{\mathrm{d}}, \underline{\mathrm{d}} & \mathrm{t}, \mathrm{d}, \mathrm{d} \\ \text { dialect A } & + & - \\ \text { dialect B } & - & + \\ \text { dialect C } & + & +\end{array}$

The programmes Proxscal and Alscal will then plot dialect $\mathrm{C}$ exactly between dialects $\mathrm{A}$ and $\mathrm{B}$ ( $\mathrm{C}$ sharing characteristics with $\mathrm{A}$ inasmuch as it shares (other) characteristics with B). Distances between the different points in the plot represent differences between dialects; the greater the distance between two points, the greater the difference between the two dialects represented.

$\begin{array}{lll}\text { o } & \text { o } & \text { o } \\ \text { A } & \text { C } & \text { B }\end{array}$

\footnotetext{
${ }^{2}$ From Nwēbi (centre of TAN territory) to Rās Ṣadr (centre of TAS territory) is approximately 200 kilometres as the crow flies.
} 


\section{Remarks to the Maps IN the AppendiX}

The maps in the appendix are ordered (with a few minor modifications) in conformity with the numbering used in De Jong 2000 (Maps referred to there are indicated in italics and with 'in 2000'). Dialect features were used as criteria for comparison between dialects and the outcome of these comparisons between dialects is illustrated in maps in the appendix of De Jong 2000. When a comparison based on the same criteria yielded no differences inside central and/or southern Sinai, no map has been drawn for that feature in the appendix of the volume in hand. Such features are, however, briefly mentioned in the remarks following below, and have been treated in the relevant paragraphs of the respective descriptive chapters of this study.

When a map was drawn for De Jong 2000, and not for the study in hand, this should be taken to mean that difference(s) with respect to the feature discussed only shows up in the dialects of the northern region discussed in De Jong 2000. References to the paragraphs discussing such features follow the remark in brackets as: '(cf. + numbering)'.

\section{a. Criteria for Comparison from De Jong 2000 Producing Differences/ Similarities in Central and Southern Sinai}

Before going into the various differences that are found in dialects of central and southern Sinai, and the maps that illustrate these differences, first a number of characteristics ${ }^{3}$ shared by all dialects in the central and southern Sinai are listed here: ${ }^{4}$

$\mathrm{NB}$, in the text below:

- 'No map in this volume' means that the feature discussed is not illustrated in a map in the appendix of this volume, since no differences were found inside central and southern Sinai for that feature set as criterion for comparison.

3 The reasons for incorporating the features listed below as a basis for dialect comparison are given in footnotes to the text in De Jong 2000:37-47.

4 Since there is little point in producing maps that only illustrate shared characteristics throughout the area, such characteristics are listed here separately. For a comparable summary of shared characteristics of dialects in northern Sinai, see De Jong 2000:30-38. To facilitate comparison I have followed the same numbering here, but have had to rearrange the order of listing in a few cases. Where additions had to be made for central and southern Sinai (when differences not found in northern Sinai do occur in this area), this is specifically mentioned. 
- 'No map' means that neither in De Jong 2000, nor in the volume in hand a map has been produced, since the feature set as criterion does not produce a difference in the entire region of Sinai).

- 'New MAP (followed by a number from 75 to 87 )' means that an additional map appears in the appendix of this volume below (for a feature for which no map appeared in De Jong 2000). The new maps for additional features set as criteria for comparison have been numbered from MAP 75 to MAP 87 (the last map-MAP 88-shows the subdivision into dialect groups in the entire region of Sinai).

- 'MAP (followed by a number from 1 to 73)' means that both in De Jong 2000, as well as in the appendix in this volume a map has been produced to illustrate differences between dialects in the entire region of Sinai. The numbering of these maps is parallel to the numbering used in De Jong 2000.

- Features used in De Jong 2000 to establish relative 'Bedouinness' or 'Sedentariness' (in a linguistic sense) of dialects under discussion are marked '(B-S)'.

- For further remarks see 'Remarks to the maps in the appendix' below.

(the numbering/capital letters used here are in reference to the list in De Jong 2000:37-47).

2. and 3. All dialects in central and southern Sinai have three interdental reflexes $\underline{t}, \underline{d}$ for respectively ${ }^{*} \underline{t},{ }^{*} \underline{d}$ and $\underline{d}$ in which * ${ }^{*}$ and ${ }^{*} \underline{\underline{d}}$ have merged (additional difference for central and southern Sinai) (cf. 1.1.2. $)^{5}$ (B-S).

No MAP 2 in this volume (MAP 2 in 200o).

No MAP 3 in this volume (MAP 3 in 20oo).

A. Like in northern Sinai, all dialects in central and southern Sinai have affricate $\check{g}$ or fricative $\check{z}$ (or both in free variation) for $* \check{g}$ (no map, cf. 1.1.4.) (B-S).

B. Like in northern Sinai, all dialects in central and southern Sinai have a voiced (unaffricated) plosive reflex $g$ for ${ }^{*} \mathrm{q}$ (no map, cf. 1.1.3.) (B-S).

${ }^{5}$ In the north dialects were identified where $\underline{d}$ and $\underline{t}$ were disappearing (Axrasiy, AxA), or had already disappeared (Biyyāḍiy, BA), see De Jong 2000:331-332 and maps 2 and 3 (in ibid., appendix). 
C. Like in northern Sinai, none of the dialects in central and southern Sinai show affrication of *k or * q (no map, cf. 1.1.3.) (B-S).

D. Like in northern Sinai, all dialects have three short vowel phonemes /i/, /u/ and /a/. The short high vowels $i$ and $u$ can be isolated through minimal pairs, but like in northern Sinai this phonemic opposition is limited (no map, cf. 1.2.3.2.) (B-S).

E. Like in northern Sinai, reduction of geminated $C_{2}\left(C_{a} C_{a}\right)$ when $C_{3}$ $\left(C_{b}\right)$ is followed by $V$, i.e. a cluster $\mathrm{C}_{a} \mathrm{C}_{a} \mathrm{C}_{b} \mathrm{~V}>\mathrm{C}_{\mathrm{a}} \mathrm{C}_{\mathrm{b}} \mathrm{V}$ : this reduction occurs regularly in all dialects of central and southern Sinai (no map, cf. 2.3.3.3.1.) (B-S).

F. See remark below.*

G. Like in northern Sinai, a preference for the construct state instead of direct annexation was not unequivocally apparent in central or southern Sinai. Instead, a comparison is made on the basis of the use of $b t \bar{a}$, šuğ l, hagg (MAP 29, cf. 3.1.11.) (B-S).

H. Like in northern Sinai, nunation (or tanwīn) is not current in any of the dialects of central and southern Sinai (no map, cf. 4.1.) (B-S).

I. Like in northern Sinai, the locative preposition $f i$ "in" occurs in all dialects of central and southern Sinai (no map, cf. 3.1.16.).

J. Like in northern Sinai, productivity of diminutive patterns is difficult to establish ${ }^{6}$ (no map, cf. 3.1.6.) (B-S).

K. Use of $m \bar{a} r$ / $m \bar{e} r$ "so, then, but", mār was heard only in MlA (no map) (B-S).

L. Use of interrogative 'alām + pron. suffix "why, what for?": like in northern Sinai, this interrogative has been recorded in several dialects, like the example 'alämuk y-Aḅuw Zēd? (GrA) "what's the matter with you, Abu Zayd" (no map, cf. 3.1.14.) (B-S).

*

F. Like in northern Sinai, the second pl. masc. pron. suffix -kuw is regular in groups I and VI, but in groups VII and VIII we have -kuw (or -kuw) -kum (or -ḳum) (see new MAP 80, 3.1.12.2.).

Of characteristics used for maps in De Jong 2000 (pp. 37-47, numbering of maps used there again runs parallel to numbering of maps presented here), the following remarks can be made for Bedouin dialects in the centre and south of Sinai.

\footnotetext{
${ }^{6}$ See remark in De Jong 2000:153, fn 237.
} 
1. $/ \mathrm{k} /$ and $/ \mathrm{k} /$ as separate phonemes in the phoneme inventory: not in group I, but both are present in phoneme inventories of groups VI-VIII (cf. 1.1.1. and 3.1.12.2.).

MAP 1 in this volume (MAP 1 in 20oo).

In northern Sinai only two tribal dialects ('AgA and SaA) showed the presence of $/ \mathrm{k} /$ as a separate phoneme. It was surmised then that this was in fact a feature more commonly present in dialects of southern Sinai. It was also reported in De Jong 200:246 that the Samānnah had migrated from the southern mountainous region of aț-Țür to the Gatyah oasis, where they reside today. This migration, as I was told one day by an older Smē'niy, would have taken place around the year 1900. ${ }^{7}$

The assumption in De Jong 2000:283-285 of / $/$ / being a more typically southern Sinaitic feature can now indeed be corroborated; we see that the southern groups VI, VII and VIII all show this separate phoneme in their phoneme inventories. The MAP also shows that in 'AgA and $\mathrm{BdA}$ the $/ \mathrm{k} /$ in the pronominal suffix - $a$. was heard with a degree of velarization, in any case a higher degree of velarization than in (other) group I dialects. In 'AgA such velarization would be attributable $-k$, resulting in a compromise form by transferring its velarization onto the new pron. suffix - $a k$ (hence $-a k$ ). In BdA velarization may be due to dialect contact; the Badārah are surrounded by Ṣawālhạah, and-no longer being on the Tìh plateau, but to the south of the escarpment in the reddish sands of ar-Ramlah near Ğabal Hmayyir ${ }^{8}$ - have considerably less contact with other group I tribes like Tiyāha, Ḥwețāt and Tarābīn (of Nwēbi').

2. and 3. See remarks made above (no maps in this volume, cf. 1.1.2.) (both B-S).

4. Secondary velarization, or emphatization: several differences were recorded in the centre and south of Sinai (cf. 1.1.7.).

MAP 4 in this volume (MAP 4 in 200o) shows the degree of velarization generally present in the dialects compared here. To illustrate this for central and southern Sinai the pl. forms of kibir and kititir are adduced.

${ }^{7}$ Von Oppenheim 1943:164 mentions that (in my translation) "parts of the 'Olēkāât have settled in Upper Egypt [...] Nowadays they mostly call themselves 'Ogēlāt". These 'Ogēlāt may well be related to the 'Agāylah (i.e. speakers of 'AgA) whom we find today as neighbours of the Samā'nah in Bīr Gațah, see map in De Jong 2000:656.

${ }^{8}$ Geographical coordinates of their current abode are appr. 29.02.53 North and 33.33.39 East. The white rectangular shapes, already plainly visible from an elevation of 1,00o metres on Google Earth, are their tents, which are made of flour sacks (donated by USAID). 
These pl. forms can be velarized, as in $k b \bar{a} r$ and $k t a \bar{a} r$, or velarization lacks and $/ \bar{a} /$ is even realized relatively high (near IPA $[\varepsilon x])$, as in $k b \bar{a} r$ and $k \underline{t} \bar{a} r$. In group VI realizations are $k b \bar{a} r$, but no velarization in $k \underline{t a ̈} r$.

5. Partial or complete monophthongization of older diphthongs *ay and *aw and possible phonemic overlapping of $/ \overline{\mathrm{e}} /$ and $/ \overline{\mathrm{i}} /$ (cf. 1.2.2.1. and 1.2.4.5.).

MAP 5 in this volume (MAP 5 in 200o) illustrates which dialects have phonetic overlapping of $/ \overline{\mathrm{e}} /$ and $/ \overline{\mathbf{1}} /$ (e.g. sêf $\sim \operatorname{sĭf}$ "sword", šêx $\sim \check{s} \bar{c} x$ "sheikh") and which dialects lack this feature.

6. Tendency to retain length of long vowels in unstressed positions. In dialects of central and southern Sinai shortening of long vowels in such positions is a feature of allegro speech (cf. 1.2.2.4.) (B-S).

No MAP 6 in this volume. MAP 6 in 2000 shows in which dialects shortening of long vowels in unstressed positions takes place. If such shortening occurs in central or southern Sinai dialects, it is a feature of allegro speech and thus clearly of a phonetic nature.

7. Raising of the short vowel $a$ in positions preceding A. (cf. 1.2.3.4.3.2., 3.1.1.5., 3.1.1.6. and 3.1.1.7.) (B-S).

MAP 7 in this volume (MAP 7 in 20oo) shows where short vowel $a$ in open syllable tends to be raised when directly preceding primarily stressed $\bar{a}$ or $a$ within word boundaries (e.g. katábt $>$ kitábt and bakāriğ > bikāriğ).

8. Raising of the feminine suffix (T) (often referred to as 'imälah of *ah). The map reflects a generalized situation (cf. 1.2.3.4.3.3.).

MAP 8 in this volume (MAP 8 in 20oo) shows the different degrees of raising of the fem. morpheme -ah (either as a pausal feature or a sandhi feature).

9. Extreme raising of final ${ }^{*}-\bar{a}$ or ${ }^{*}-\vec{a}>-i y$, or less extreme raising $>-i$ (MAP 9, cf. 1.2.4.4.) (B-S).

MAP 9 in this volume (MAP 9 in 20oo) illustrates the different reflexes of final $-\bar{a}\left({ }^{\prime}\right)$ in neutral (i.e. non-velarized) environments encountered in Sinai.

10. Absence of raising of final $-\bar{a}$ or $-\vec{a}$ (MAP 10, cf. 1.2.4.4.).

MAP 10 in this volume (MAP 10 in 200o) shows reflexes of final $-\bar{a}\left({ }^{\prime}\right)$ in non-raised positions.

11. Diphthongal reflexes of *ay and *aw (cf. 1.2.4.1., 1.2.4.6. and 1.2.4.7.). MAP 11 in this volume (MAP 11 in 2000) shows the reflexes of diphthongs *ay and *aw when directly preceded by back spirants $(\mathrm{X})$ or emphatics (M) present in Sinai dialects. 
12. Stress in mediae geminatae where the geminate is word-final. (cf. 2.1.1.).

No MAP 12 in this volume. MAP 12 in 2000 shows stress in forms with final geminates. In central and southern Sinai the vowel directly preceding a final geminate is invariably stressed (e.g. yhutt "he places", tšidd "you pull", tinhátț "it (sg. fem.) is placed", aššáț or iššáț "the coast") and thus the whole central and southern region shows no difference in this respect.

13. Stress in maCCaCah (cf. 2.1.1.1.).

No MAP 13 in this volume. MAP 13 in 2000 shows stress assignment in the pattern maCCaCah. All dialects in central and southern Sinai have the máCCaCah stress-type.

14. Stress in ${ }^{*} \mathrm{CaCvC}$ (i.e. surface forms $\mathrm{CvCaC}, \mathrm{CvCiC}$ or $\mathrm{CvCuC}$ ) (cf. 2.1.1.2.).

MAP 14 in this volume (MAP 14 in 200o) illustrates stress assignment in patterns $\mathrm{CiCiC}$ (including $\mathrm{CuCuC}$; both being 'underlying' $\mathrm{CaCi} / \mathrm{uC}$ ) and $\mathrm{CaCaC}$.

15. Stress in ${ }^{*} \mathrm{CaCaCv}$ (cf. 2.1.1.2.1.).

MAP 15 in this volume (MAP 15 in 2000) shows stress assignment in the pattern $\mathrm{CaCaCv}$.

16. Stress in ${ }^{*} \mathrm{CaCaCaCv}$ (MAP 16, cf. 2.1.1.2.2., was 2.1.1.2.1.3. in De Jong 2000).

MAP 16 in this volume (MAP 16 in 200o) shows stress assignment in the pattern $\mathrm{CaCaCaCv}$.

17. Resyllabication of ${ }^{*} \mathrm{CaCaCV}$ sequences. Such resyllabication is not a feature of any of the dialects of central and southern Sinai, e.g. waragah "piece of paper", gahawah "coffee" (cf. 2.1.1.2.2., was 2.1.1.2.1.6. in De Jong 2000) (B-S).

No MAP 17 in this volume. MAP 17 in 2000 shows the presence/absence of the Nağdiy type of resyllabification: $\mathrm{CaCaCV}>\mathrm{CCvCV}$. This type of resyllabification was not heard in central or southern Sinai.

18. The article and preformatives of measures $n-1$ and 1- $t$ as stressable units (cf. 2.1.1.2.2.) (B-S).

MAP 18 in this volume (MAP 18 in 200o) shows stress assignment in verbal measures $n-1$ (of VII) and 1- $t$ (or VIII) and in sequences (with article) alCaCaC.

19. The gahawah-syndrome (cf. 2.2.1. and 2.2.1.3.) (B-S). No MAP 19 in this volume. MAP 19 in 2000 shows the spread of the gahawah-syndrome. The syndrome is active in all dialects of central and southern Sinai. 
20. Presence of initial CCV in a limited number of morphological patterns (cf. 2.3.5.) (B-S).

MAP 20 in this volume (MAP 20 in 20oo) shows reflexes of the pattern ${ }^{*} \mathrm{CICaC}$.

21. Raising of $a$ in $\mathrm{CaC}_{1} \mathrm{iC}_{3}$ ah (cf. 1.2.3.4.3.2. and 3.1.1.1.).

MAP 21 in this volume (MAP 21 in 200o) shows raising (or absence of it) of short vowel $a$ in pre-stress open syllable in a sequence $\mathrm{CaCīC}(\mathrm{ah})$.

22. Raising of $a$ in ${ }^{*} \mathrm{CaCCāC} \mathrm{(cf.} \mathrm{1.2.3.4.3.2.} \mathrm{and} \mathrm{3.1.1.4.).}$

MAP 22 in this volume (MAP 22 in 200o) shows raising (or absence of it) of short vowel $a$ in a pre-stress closed syllable in a sequence CaCCāC(ah).

23. Raising of $a$ in open syllable preceding $\bar{u}$ (cf. 1.2.3.4.3.2. and 3.1.1.8.). MAP 23 in this volume (MAP 23 in 200o) shows raising (or absence of it) of short vowel $a$ in pre-stress open syllable in a sequence $\mathrm{CaCūC}(\mathrm{ah})$.

24. The pattern for colours and physical defects (cf. 3.1.7.).

No MAP 24 in this volume. MAP 24 in 2000 shows reflexes of the pattern *aCCaC for colours and physical defects. In southern and central Sinai the current reflex for this pattern is aCCaC in all dialects.

25. The definite article and the relative pronoun (cf. 3.1.9.1.) (B-S).

MAP 25 in this volume (MAP 25 in 200o) shows the form of the article and the relative pronoun.

26. Occurrence of $/ \mathrm{a} /$ in the initial syllable of a number of irregular nouns (cf. 3.1.9.2.).

MAP 26 in this volume (MAP 26 in 20oo) is on the short initial vowels in the lexemes for "mother" and "sister".

27. Treatment of $\mathrm{T}$ (the feminine suffix morpheme) (cf. 3.1.10.).

MAP 27 in this volume (MAP 27 in 200o) shows the behaviour of the fem. morpheme $(\mathrm{T})$ in construct state.

28. Elision of the T-vowel in construct state (cf. 3.1.10.).

MAP 28 in this volume (MAP 28 in 20oo) is on the elision of the short vowel of the fem. morpheme (the T-vowel).

29. The genitive exponent (cf. 3.1.11.).

MAP 29 in this volume (MAP 29 in 20oo) shows the different genitive exponents used for the analytical genitive in Sinai dialects.

30. Gender distinction masc./fem. in 2nd and 3rd p. pl. (cf. 3.1.12., 3.2.1.1., 3.2.1.2.) (B-S).

No MAP 30 in this volume. MAP 30 in 2000 is on the absence or presence of gender distinction masc./fem. in plurals of personal pronominals, adjectives and verb forms. In all dialects of central and southern Sinai this distinction is made. 
31. The independent personal pronominals of the 3 rd p. sg. masc. and fem. (cf. 3.1.12.1.).

MAP 31 (MAP 31 in 200o) is on the shapes of the pronominals for the 3rd p. masc. sg, and the 3 rd p. sg. fem. "he" and "she".

32. The 1st p. sg. com. pronominal (cf. 3.1.12.1.).

No MAP 32 in this volume. MAP 32 in 2000 is on the shape of the pers. pronominal for the ist person sg. com. "I". The form used in the entire central and southern Sinai is ana, stressed either on the first or on the second syllable (covered in MAP 14).

33. The ist p. pl. com. personal pronominal (cf. 3.1.12.1.). MAP 33 (MAP 33 in 200o) is on the shape of the pers. pronominal for the ist person pl. com. "we".

34. The pronominal suffix for the 3 rd p. sg. masc. (cf. 3.1.12.2.) (B-S).

$\mathrm{MAP}_{34}\left(\mathrm{MAP}_{34}\right.$ in 20oo) is on the shape of the pronominal suffix (obj. or poss.) for the 3 rd person sg. masc. "him (obj.)" or "his (poss.)".

35. The pronominal suffix for the 3 rd p. sg. fem. (cf. 3.1.12.2.).

MAP 35 (MAP 35 in 200o) is on the shape of the pronominal suffix (obj. or poss.) for the 3 rd person sg. fem. "her".

36. The pronominal suffix for the 2nd p. sg. masc. (cf. 3.1.12.2.). $\mathrm{MAP}_{3} 6\left(\mathrm{MAP}_{3} 6\right.$ in 20oo) is on the shape of the pronominal suffix (obj. or poss.) for the 2 nd person sg. masc. "you (obj.)" or "your (poss.)".

37. The pronominal suffix for the 2nd p. sg. fem. (cf. 3.1.12.2.).

MAP 37 (MAP 37 in 20oo) is on the shape of the pronominal suffix (obj. or poss.) for the 2nd person sg. fem. "you (obj.)" or "your (poss.)".

38. The pronominal suffix for the 1st p. sg. com. (cf. 3.1.12.2.).

No MAP 38 in this volume. MAP 38 in 2000 is on the shapes of the pronominal suffixes (obj. and poss.) for the 1st person sg. com. In all of central and southern Sinai "me (obj.)" or "my (poss.)" (stressed) $\bar{\imath}$ (possessive) and (stressed) $-n \bar{\imath}$ (object) (usually $\sim$ unstressed $-i$ and $-n i$ ).

39. Emphatization of $\underline{d}$ in demonstratives of near deixis if not followed by $-i$ (cf. 3.1.13.) (B-S).

MAP 39 (MAP 39 in 2000) gives the demonstratives for sg. masc. near deixis "this".

40. The sg. fem. demonstrative (cf. 3.1.13.).

MAP 40 (MAP 40 in 200o) gives the demonstratives for sg. fem. near deixis "this".

41. Gender distinction in pl. demonstratives (cf. 3.1.13.1.) (B-S).

No MAP 41 in this volume. MAP 41 in 2000 is on gender distinction in pl. demonstratives. In central and southern Sinai no such distinction is made, except in MzA, but material is insufficient for definitive conclu- 
sions. In MAP 32 the pl. com. forms of demonstratives are given for central and southern Sinai (information is incomplete for northern Sinai).

42. Interrogative "who?" (cf. 3.1.14.) (B-S).

MAP 42 (MAP 42 in 200o) compares the different shapes of the interrogative "who?".

43. Interrogative "where?" (cf. 3.1.14.) (B-S).

No MAP 43 in this volume. MAP 43 in 2000 is on the shapes of the interrogative "where?" In central and southern Sinai this interrogative is wēn in every dialect.

44. Interrogative "how?" (cf. 3.1.14.) (B-S).

No MAP 44 in this volume. MAP 44 in 2000 is on the different forms for the interrogative "how?" In central and southern Sinai the current form is $k \bar{e} f$ or $k \bar{i}$.

45. Adverb "there" (cf. 3.1.15.1.) (B-S).

MAP 45 (MAP 45 in 200o) gives forms used for the adverb "there".

46. Shape of the adverb "here" (cf. 3.1.15.1.) (B-S).

MAP 46 (MAP 46 in 20oo) gives forms used for the adverb "here".

47. The preposition l "to" + 3rd p. sg. masc. suffix (cf. 3.1.16.) (B-S).

MAP 47 (MAP 47 in 200o) compares the different varieties of the preposition "to" + 3rd person. sg. masc. suffix: "to him".

48. The preposition $m(a)^{c}$ "with" + 3rd p. sg. masc. suffix (cf. 3.1.16.). MAP 48 (MAP 48 in 200o) gives the different varieties of the preposition "with" + 3rd person sg. masc. suffix: "with him".

49. Numeral "one (fem.)" (cf. 3.1.17.).

No MAP 49 in this volume. MAP 49 in 2000 shows forms of the sg. fem. numeral "one", The form wihdih is current throughout central and southern Sinai.

50. The 3 rd p. pl. masc. verbal ending of $a$-type perfects (cf. 3.2.1.1.). MAP 50 (MAP 50 in 200o) is on presence/absence of vowel harmony in verbal endings of the 3 rd person pl. masc. perfect.

51. The 3 rd p. pl. fem. verbal ending of $a$-type perfects (cf. 3.2.1.1.).

MAP $5^{1}$ (MAP $5^{1}$ in 200o) is on the presence/absence of vowel harmony in verbal endings of the 3 rd person pl. fem. $a$-type perfect.

52. The $i$-type perfect (cf. 2.1.1.2.2. and 3.2.1.1.).

MAP $5^{2}\left(M^{2} 5^{2}\right.$ in 2000$)$ is on the $i$-type perfect of verbs ${ }^{*} \mathrm{CaCiC}: 3^{\text {rd }}$ person sg. masc., 3rd person sg. fem. and 1st person sg. com.

53. Vowel harmony in the preformative of the imperfect of verbal measure 1. (cf. 3.2.1.2.) (B-S).

No MAP 53 in this volume. MAP 53 in 2000 is on the absence/presence of vowel harmony in the preformative of the $a$-type imperfect: 
yaCCaC or yiCCaC. All dialects of central and southern Sinai show such vowel harmony, e.g. yašrab "he drinks".

54. The 3 rd p. pl. masc. verbal endings of $a$-, $i$ - and $u$-types imperfects (cf. 3.2.1.2.).

MAP 54 (MAP 54 in 2000) is on the presence/absence of vowel harmony in verbal endings of the 3 rd person pl. masc. endings in $a^{-}, i^{-}$ and $u$-type imperfect.

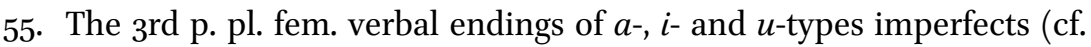
3.2.1.2.).

MAP 55 (MAP 55 in 200o) is on presence/absence of vowel harmony (i.e. low short vowel $a$ or high short vowel $i$ ) in verbal endings of the 3 rd person pl. fem. in $a$-, $i$ - and $u$-type imperfect.

56. Imperfect preformative of measure 1 primae $w \bar{a} w$ verbs (cf. 3.2.2.1.) (B-S).

No MAP 56 in this volume. MAP 56 in 2000 is on the vowel in the imperfect preformative of primae $w \bar{a} w$ measure 1 verbs. This vowel is not $i$ (as in e.g. yiwșal) in central or southern Sinai dialects, but $a$ as in yawșal, or $(a w>)$ monothongized to $\bar{o}(\sim \bar{u})$ as in yōsal.

57. Perfect of primae hamzah verbs (cf. 3.2.2.3.).

MAP 57 (MAP 57 in 200o) shows the (3rd person sg. masc.) perfect forms of primae hamzah measure 1 verbs: with or without initial $a-$.

58. Imperfect vowel in primae hamzah verbs (cf. 3.2.2.3.).

MAP 58 (MAP 58 in 200o) is on the vowel $i$ or $u$ in the (3rd person sg. masc.) imperfect forms of primae hamzah measure 1 verbs.

59. The active participle of primae hamzah measure 1 verbs (cf. 3.2.2.3.). No MAP 59 in this volume. MAP 59 in 2000 shows the forms of the active participle of primae hamzah measure 1 verbs. In central and southern Sinai these are with initial $m \bar{a}-: m \bar{a} k i l, m \bar{a} x i d$.

6o. 3rd p. sg. masc. perfect of the verb "come" (cf. 3.2.2.6.1.).

No MAP 60 in this volume. MAP 60 in 2000 compares perfect forms of the verb "come": 3 rd person sg. masc., 1st person sg. com., 3rd person pl. masc. and 3 rd person pl. fem. In none of the dialects of central and southern Sinai initial $i$ - or $\bar{\imath}$ - (i.e. iğa or ĭğa for "he came") is current.

61. Imperfect of the verb "come". (cf. 3.2.2.6.1.).

MAP 61 (MAP 61 in 200o) gives imperfect forms of the verb "come": 3rd person sg. masc., 1st person sg. com.: with or without lengthened preformative vowel.

62. Measures $n-1,1-t$ and (a)sta-1 or (i)sta-1 (cf. 3.2.3.1.1. and 3.2.3.3.1.). MAP 62 (MAP 62 in 20oo) is on occurrence of initial $a$ - in the preformatives of measures $n-1$ and $1-t$ perfect and on imperfect. 
63. Measure (a)sta-1 or (i)sta-1 perfect and imperfect (cf. 3.2.3.4.1.).

No MAP 63 in this volume. MAP 63 in 2000 is on measures (i)sta-1: perfect and imperfect. In all dialects of the central and southern Sinai the patterns $(\mathrm{i}) \operatorname{staC}_{1} \mathrm{C}_{2} \mathrm{aC}_{3}$, yistaC $\mathrm{C}_{2} \mathrm{iC}_{3}$ with morphologically alternating vowels $a$ and $i$ are current.

64. Measure $t a-2$ or (i)t-2 (cf. 3.2.3.5.4.).

No MAP 64 in this volume. MAP 64 in 2000 is on measures ta-2 or $t$-2: perfect and imperfect. In the entire central and southern Sinai reducing the preformative $t a$ - to $(i) t$ - may at times occur, but it is not current.

65. Frequency of use of measure 4 verbs (cf. 3.2.3.7.) (B-S).

No MAP 65 in this volume. MAP 65 in 2000 is on presence/ absence of measure 4 . In the entire central and southern Sinai an active verbal measure 4 is current.

66. Typical Bedouin verbs of the $\mathrm{C}_{1} \mathrm{awC}_{2} \mathrm{aC}_{3}, \mathrm{yC}_{1} \mathrm{awC}_{2} \mathrm{iC}_{3}$-type (cf. 3.2.3.9.) (B-S).

No MAP 66 in this volume. MAP 66 in 2000 is on the typically 'Bedouin' verb-type with inserted $w \bar{a} w \mathrm{C}_{1} \bar{o} \mathrm{C}_{2} \mathrm{aC}_{3}\left(\right.$ or $\left.\mathrm{C}_{1} \mathrm{awC}_{2} \mathrm{aC}_{3}\right), \mathrm{yC}_{1} \bar{o} \mathrm{C}_{2} \mathrm{iC}_{3}$ (or $\mathrm{yC}_{1} \mathrm{awC}_{2} \mathrm{iC}_{3}$ ). In the entire central and southern Sinai this verbtype occurs regularly.

67. The sg. fem. active participle + object suffix in construct state (cf. 3.2.1.4.) (B-S).

No MAP 67 in this volume. MAP 67 in 2000 is on sg. fem. act. participles followed by an obj. suffix: a construct state results, or does not. In all dialects of central and southern Sinai a contruct state will result, e.g. hì mrìdtah or rāyidtah "she wants him".

68. Negation: single $m \bar{a}$ or compound $m a \ldots . .+\check{s}$ (cf. 4.2.) (B-S).

MAP 68 (MAP 68 in 200o) is on verbal negation: is $m \bar{a}+$ verb form used, or compound $m \bar{a}+$ verb form $+\check{s}$ ?

69. Use of the $b$-imperfect for the habitual present tense (cf. 4.3.) (B-S).

No MAP 69 in this volume. MAP 69 in 2000 is on use of the $b$-imperfect. The $b$-imperfect is current in all dialects of central and southern Sinai.

70. Future particle ha- (cf. 4.4.).

No MAP 70 in this volume. MAP 70 in 2000 is on use of the future particle. The future particle $h a$ - may be heard in all dialects of central and southern Sinai.

71. Use of yōm(-in) or lōm(-in) "when" (cf. 4.6.) (B-S).

MAP 71 (MAP 71 in 200o) is on the occurrence of yōm, lōm for the conjunction "when". These forms are regular in all dialects of central and southern Sinai. 
72. Marker of consequent action (unconjugated) gām (cf. 4.7.1.). MAP 72 (MAP 72 in 20oo) is on the occurrence of $g \bar{a} m$ as a "marker of consequent action" for the conjunction "when". This gām is not regular in central or southern Sinai dialects; only in 'LA it was recorded a few times.

73. Use of widd or bidd (cf. 4.11.) (B-S).

MAP 73 (MAP 73 in 200o) is on the use of widd or bidd to express "want" or "need".

74. No MAP 74 in this volume. MAP 74 in 2000 shows the dialect groups identified in northern Sinai. A map showing dialect groups in the entire Sinai is MAP 88 in the appendix of the volume in hand.

\section{b. Added Criteria for Comparison of Dialects in Central and}

\section{Southern Sinai}

In addition to comparisons based on the 73 features listed above, a total of 13 features are added here to serve as criteria for comparison to further illustrate differences/similarities in dialects of central and southern Sinai. These features (numbered $75^{-87}$ ) are listed below:

75. Raising of $a$ in closed syllable preceding stressed $\bar{e}$ : lammèt $>$ limmèt, sawwèt > suwwèt (new MAP 75 in this volume, cf. 1.2.3.4.3.2., 3.2.3.5.2. and 3.2.2.7.1.).

76. Raising of $a$ in open syllable preceding stressed $\bar{e}$ : mašèt $>$ mišèt (new MAP 76 in this volume, cf. 1.2.3.4.3.2., 3.2.2.5.1.).

77. Mutual influence of hissing sounds: metathesis in forms like șāg — $̌ \bar{a} z$ and siğih-šızih (new MAP 77 in this volume, cf. 2.5.).

78. The pl. masc. personal pronominal "they" (new MAP 78 in this volume, cf. 3.1.12.1.).

79. Negated personal pronominals "not he", "not she", "not you (sg. masc.)", "not I" (new MAP 79 in this volume, cf. 3.1.12.1.).

8o. The 2nd p. pl. masc. pronominal suffix (new MAP 80 in this volume, cf. 3.1.12.2.).

81. The pl. com. demonstrative "these" (new MAP 81 in this volume, cf. 3.1.13.1.).

82. Interrogative "when?" (new MAP 82 in this volume, cf. 3.1.14.).

83. Shape of the preposition 'ala "on" with 3 rd p. sg. masc. suffix (new MAP 83 in this volume, cf. 3.1.16.).

84. The 2nd p. sg. masc. imperfect of mediae geminatae verbs (new MAP 84 in this volume, cf. 3.2.2.4.1.). 
85. The sg. masc. imperative of mediae geminatae verbs (new MAP 85 in this volume, cf. 3.2.2.4.2.).

86. The 3 rd p. sg. masc. perfect of tertiae $y \bar{a}^{\prime}$ verbs (new MAP 86 in this volume, cf. 1.2.4.4., 3.2.2.5.1.).

87. The apocopated 2nd p. sg. masc. of tertiae infirmae imperfect (new MAP 87 in this volume, cf. $3 \cdot 2.2 \cdot 5 \cdot 1$.$) .$

\section{IsOGLOSSES}

\section{a. The Identified Isoglosses in Central and Southern Sinai}

Below follows a list of isoglosses which result from the comparison of dialects based on features treated in the maps in the appendix, which were set as criteria for this comparison. The numbering of the criteria corresponds with the numbering of the MAPS in the appendix. The numbering of the criteria (nrs 1-73) here again corresponds to the numbering used in De Jong 2000:600-601. ${ }^{9}$ In addition to these, criteria nrs $75^{-87}$ (in MAPS $75^{-87}$, see preceding paragraph) illustrate further differences between dialects in the centre and south of Sinai.

In some cases - mainly where new features were set as criteria for comparison within the centre and south of Sinai-the data for the dialects in this comparison were incomplete; the dialects discussed in De Jong 2000, which now border on our more northern dialects discussed here, were not compared before on the basis of the additional criteria introduced for the dialects discussed here.

The totals of differences listed below have been calculated as follows: a partial difference has been counted as half in the total; often parallel forms result from dialect contact, so that one form may be identical to a form heard in a neighbouring dialect, while parallel to this form (in the same meaning) another form was heard, which was not heard in the same neighbouring dialect.

In cases where the comparison was incomplete due to the lack of data in one (or both) of the dialects compared, the uncertain outcome has been counted as half as well. The total numbers of isoglosses were calculated to be drawn into MAP o in the appendix.

9 N.B. the numbering of the isogloss bundles here does not correspond to the numbering of isogloss bundles in De Jong 2000. 
The percentages listed below were however calculated on the basis of a corrected total; uncertain outcomes have been subtracted from the total of the 95 features serving as criteria for comparison. Isogloss bundle number -1- may serve as an example: we count 4 full differences and 5 partial differences. These add up to $(4+2.5=) 6.5$ differences. We also count seven uncertain differences. From the total of 95 we subtract this 7 , which brings the corrected total to 88 . We then calculate 6.5 as a percentage of 88: $(6.5: 88)^{*} 100=7.386364$. This is rounded off to be $7.4 \%$. This means that $7.4 \%$ of a total of 88 features set as criteria for comparison between the two (geographically bordering) dialects yield differences. These percentages were calculated to be used in the 'step method' calculation.

\section{N.B.}

* The absolute numbers of isoglosses drawn into MAP o as bundles cannot be compared to the absolute numbers forming isogloss bundles drawn in MAP o in De Jong 200o, since the two maps illustrate comparisons based on different totals of dialect features set as criteria for comparison.

* The numbers between hyphens refer to the numbering of isogloss bundles in MAP o in the appendix (these numbers are not related to the numbering of isogloss bundles in De Jong 2000). The numbers followed by a bracket ) refer to the numbering of the maps in the appendix in De Jong 2000 and in the appendix of this volume (but the maps numbered $75^{-8} 7$ only appear in the volume in hand).

-1- Isogloss bundle $\mathrm{nr}-1$ - distinguishes SA from MlA.

4 differences: 23$), 39), 48), 87$ )

7 uncertain differences: 4), 27), 37), 72), 77), 79), 82)

5 partial differences: 14), 45), 46), 47), 78)

Total 10 differences; percentage of corrected total $(=88) 7.4 \%$

-2- Isogloss bundle $\mathrm{nr}-2$ - distinguishes MlA from nTA.

2 differences: 16$), 58$ )

11 uncertain differences: 4), 23), 57), 72), 76), 77), 78), 79), 81), 82), 87)

5 partial differences: 14), 40), 45), 46), 47)

Total 10 differences; percentage of corrected total $(=84) 5.4 \%$ 
-3- Isogloss bundle $\mathrm{nr}-{ }^{-}$- distinguishes nTA from TyA.

5 differences: 21), 48), 52), 58), 83)

9 uncertain differences: 4), 27), 72), 76), 77), 79), 81), 82), 87)

4 partial differences: 14), 15), 23), 86)

Total 11,5 differences; percentage of corrected total $(=86) 8.1 \%$

-4- Isogloss bundle $\mathrm{nr}-4$ - distinguishes 'AyA from Aḥ.

4 differences: 16), 23), 52), 85)

9 uncertain differences: 4), 27), 57), 72), 76), 77), 79), 82), 87)

6 partial differences: 14), 15), 35), 46), 48), 58)

Total 11,5 differences; percentage of corrected total $(=86) 8.1 \%$

-5- Isogloss bundle $\mathrm{nr}-5^{-}$distinguishes 'AyA from HiwA.

7 (minus $1^{*}$ ) differences: 11), 16), 33), 39), 52), 75), 83)*

10 uncertain differences: 4), 27), 57), 72), 76), 77), 79), 81), 82), 87)

5 partial differences: 14$), 15), 35), 48), 58$ )

* The difference is in raising of a ('alēh > 'ilèh), which is already covered in MAP 76 ).

Total 13,5 differences; percentage of corrected total $(=85) 10 \%$

-6- Isogloss bundle $\mathrm{nr}$-6- distinguishes ḤwA from AḥA.

11 (minus $1^{*}$ ) differences: 11), 23), 33), 35), 39), 72), 75), 76), 82), 83)*, 85)

1 uncertain difference: 27 )

1 partial difference: 46 )

* The difference is in raising of a ('alēh > 'ilēh), which is already covered in MAP 76 ).

Total 10.5 differences; percentage of corrected total $(=94) 11.1 \%$

-7- Isogloss bundle $\mathrm{nr}-7-$ distinguishes ḤwA from TAṢ.

16 (minus $1^{*}$ ) differences: 5), 7), 15), 16), 21), 22), 33), 39), 52), 57), 71), 75), 76), 81), 82), 83)*

o uncertain differences

1 partial difference: 25 ) 
* The difference is in raising of $a$ ('alēh > 'ilēh in 83)), which is already covered in MAP 76).

Total 15,5 differences; percentage of corrected total (= 95) 16.3\%

-8- Isogloss bundle $\mathrm{nr}-8$ - distinguishes TyA from AḥA.

8 differences: 21), 23), 48), 72), 76), 81), 83), 87)

2 uncertain differences: 27), 82)

2 partial differences: 46 ), 86)

Total 10 differences; percentage of corrected total (=93) 9.7\%

-9- Isogloss bundle $\mathrm{nr}$-9- distinguishes AhA from DbA.

8 differences: 21), 23), 48), 72), 76), 81), 83), 87)

2 uncertain differences: 27), 82)

2 partial differences: 46 ), 86)

Total 10 differences; percentage of corrected total (=93) 9.7\%

-10- Isogloss bundle $\mathrm{nr}-10-$ distinguishes DbA from TyA.

6 differences: 21), 35), 48), 75), 82), 87)

o uncertain differences

1 partial difference: 81 )

Total 6,5 differences; percentage of corrected total $(=95) 6.8 \%$

-11- Isogloss bundle nr -11- distinguishes TAṢ from ĞrA.

9 differences: 15), 16), 22), 71), 75), 76), 81), 83), 87)

o uncertain differences

3 partial differences: 7), 26), 33)

Total 10,5 differences; percentage of corrected total (= 95) $11 \%$

-12- Isogloss bundle $\mathrm{nr}-12-$ distinguishes ĞrA from Ḥ̂.

8 differences: 5), 21), 39), 52), 57), 82), 83), 87)

0 uncertain differences

3 partial differences: 25), 26), 33)

Total 9,5 differences; percentage of corrected total $(=95) 10 \%$ 
-13- Isogloss bundle $\mathrm{nr}-13^{-}$distinguishes TAṢ from 'LA.

37 (minus $2^{*}$ ) differences: 1), 4), 9), 10), 11), 22), 23), 26), 31), 34), 35), $\left.\left.\left.\left.\left.\left.\left.\left.36), 37), 39), 40), 42), 46), 47)^{*}, 48\right), 50\right), 54\right), 55\right), 60\right), 61\right), 62\right), 71\right), 72$ ), $73), 75), 76), 77), 79), 80), 81), 82), 83)^{*}, 87$ )

o uncertain differences

5 partial differences: 7$), 8), 14), 45), 58)$

* The difference of the different 3 rd p. sg. masc. pron. suffix in 47) and 83) is already covered in MAP 34 .

Total 37,5 differences; percentage of corrected total (= 95) 39.5\%

-14- Isogloss bundle $\mathrm{nr}-14$ - distinguishes ĞrA from 'LA.

34 (minus $2^{*}$ ) differences: 1), 4), 7), 9), 10), 11), 15), 16), 23), 31), 34), $\left.\left.\left.\left.\left.\left.\left.35), 36), 37), 39), 40), 42), 46), 47)^{*}, 48\right), 50\right), 54\right), 55\right), 60\right), 61\right), 62\right), 72$ ), 73), 77), 79), 80), 81), 82, 83)*

o uncertain differences

6 partial differences: 8), 14), 26), 33), 45), 58)

* The difference of the different 3 rd p. sg. masc. pron. suffix in 47) and 83) is already covered in MAP 34 .

Total 35 differences; percentage of corrected total (= 95) 36.8\%

-15- Isogloss bundle $\mathrm{nr}-15^{-}$distinguishes HwA from TyA.

9 differences: 11), 21), 33), 35), 39), 48), 75), 82), 87)

o uncertain differences

2 partial differences: 81), 86)

Total 10 differences; percentage of corrected total $10 \%$

-16- Isogloss bundle $\mathrm{nr}-16-$ distinguishes 'LA from HwA.

40 (minus $1^{*}$ ) differences: 1), 4), 5), 7), 8), 9), 10), 11), 15), 21), 23), 26), $\left.\left.\left.\left.\left.31), 33), 34), 35), 36), 37), 40), 42), 46), 47)^{*}, 48\right), 50,52\right), 54\right), 55\right), 57\right)$, $60), 61), 62), 72), 73), 77), 79), 80), 81), 82), 83), 87$ )

o uncertain differences

6 partial differences: 14), 16), 25), 39), 45), 58)

* The difference of the different 3 rd p. sg. masc. pron. suffix in 47) is already covered in MAP 34 .

Total 42 differences; percentage of corrected total (= 95) $44.2 \%$ 
-17- Isogloss bundle $\mathrm{nr}-17-$ distinguishes HwA from BdA.

11 (minus $1^{*}$ ) differences: 21), 26), 33), 39), 75), 76), 81), 82), 83)*, 85), 87)

0 uncertain differences

2 partial differences: 42 ), 78 )

* The difference is in raising of $a$ ('alēh > 'ilēh in 83)), which is already covered in MAP 76 ).

Total 11 differences; percentage of corrected total (=95) 11.6\%

-18- Isogloss bundle $\mathrm{nr}-18$ - distinguishes BdA from TyA.

8 (minus $1^{*}$ ) differences: 11), 26), 35), 48), 76), 81), 83)*, 85)

0 uncertain differences

3 partial differences: 42 ), 78), 86)

* The difference is in raising of a ('alēh > 'ilēh in 83)), which is already covered in MAP 76).

Total 8,5 differences; percentage of corrected total $(=95) 8.9 \%$

-19- Isogloss bundle $\mathrm{nr}-19$ - distinguishes AhA from TAN.

10 differences: 5), 11), 21), 22), 23), 35), 48), 72), 81), 85)

1 uncertain difference: 27 )

2 partial differences: 42), 78)

Total 11 differences; percentage of corrected total (= 94) 11.7\%

-20- Isogloss bundle $\mathrm{nr}-20$ - distinguishes 'LA from BdA.

39 (minus $1^{*}$ ) differences: 1), 4), 5), 7), 8), 9), 10, 11), 15), 16), 23), 31), $\left.\left.\left.\left.\left.\left.34), 35), 36), 37), 39), 40), 46), 47)^{*}, 48\right), 50\right), 5^{2}\right), 54\right), 55\right), 57\right), 60$ ), $61), 62), 72), 73), 75), 76), 77), 79), 80), 82), 83), 85$ )

0 uncertain differences

7 partial differences: 14), 25), 42), 45), 58), 78), 81)

* The difference of the different 3 rd p. sg. masc. pron. suffix in 47) is already covered in MAP 34 .

Total 41,5 differences; percentage of corrected total $(=95) 43.7 \%$

-21- Isogloss bundle $\mathrm{nr}-21$ - distinguishes TyA from TAN.

8 (minus $1^{*}$ ) differences: 5), 11), 22), 35), 76), 81), 83)*, 87)

0 uncertain differences 
4 partial differences: 42), 46), 78), 86)

* The difference is in raising of $a$ ('alēh > 'ilēh in 83)), which is already covered in MAP 76).

Total 9 differences; percentage of corrected total (= 95) 9.5\%

-22- Isogloss bundle $\mathrm{nr}-22-$ distinguishes 'LA from ḤmA.

6 differences: 4), 31), 47), 6o), 72), 79)

o uncertain differences

8 partial differences: 14), 18), 45), 68), 81), 83), 84), 86)

Total 10 differences; percentage of corrected total $(=95) 10.5 \%$

-23- Isogloss bundle $\mathrm{nr}-23^{-}$distinguishes 'LA from ȘwA.

11 differences: 4), 18), 20), 37), 48), 68), 71), 72), 83), 84), 85)

o uncertain differences

8 partial differences: 7), 14), 25), 50), 54), 58), 79), 81)

Total 15 differences; percentage of corrected total $(=95) 15.8 \%$

-24- Isogloss bundle $\mathrm{nr}$-24- distinguishes BdA from ṢwA.

46 (minus $2^{*_{1} *_{2}}$ ) differences: 1), 4), 5), 7), 8), 9), 10), 11), 14), 15), 16), 18), 20), 23), 25), 31), 34), 35), 36), 37), 39), 40), 46), 47), 48$), 5^{0}, 5^{2}$ ), $54), 55), 57), 58), 60), 61), 62), 68), 71), 73), 75), 76), 77), 79), 80), 82$ ), $\left.\left.83)^{* 2}, 84\right), 85\right)$

0 uncertain differences

3 partial differences: 42$), 45), 78$ )

$*_{1}$ The difference of the different 3 rd p. sg. masc. pron. suffix in 47) is already covered in MAP 34 .

$*_{2}$ The difference is in raising of $a$ ('alēh > 'ilēh in 83)), which is already covered in MAP 76 ).

Total 45,5 differences; percentage of corrected total (= 95) 47.9\%

-25- Isogloss bundle $\mathrm{nr}-25^{-}$distinguishes 'LA from GrA.

11 differences: 4), 18), 20), 22), 48), 68), 71), 72), 83), 84), 85)

o uncertain differences

10 partial differences: 14), 25), 37), 39), 40), 46), 50), 54), 58), 81)

Total 16 differences; percentage of corrected total $16.8 \%$ 
-26- Isogloss bundle $\mathrm{nr}-26$ - distinguishes ȘwA from GrA.

1 difference: 22 )

o uncertain differences

5 partial differences: 7), 39), 40), 46), 79)

Total 3,5 differences; percentage of corrected total $(=95) 3 \cdot 7 \%$

-27- Isogloss bundle $\mathrm{nr}$-27- distinguishes ȘwA from MzA.

25 (minus $2^{*}$ ) differences: 4), 7), 8), 11), 14), 18), 20), 22), 26), 31), 48), $\left.\left.\left.\left.\left.\left.\left.\left.\left.\left.\left.\left.\left.\left.5^{2}\right), 57\right), 5^{8}\right), 61\right), 62\right), 68\right), 71\right), 78\right), 79\right), 80\right), 82\right), 84\right)^{*}, 85\right)^{*}, 86\right)$

0 uncertain differences

8 partial differences: 16), 25), 27), 28), 29), 42), 46), 81)

* The difference here is mainly in stress, which is already covered in MAP 14.

Total 27 differences; percentage of corrected total (= 95) $28.4 \%$

-28- Isogloss bundle $\mathrm{nr}-28$ - distinguishes MzA from TAN.

35 (minus $3^{*_{1} *_{2}}$ ) differences: 1), 4), 9), 10), 15), 16), 22), 23), 27), 34), $\left.\left.\left.\left.\left.\left.\left.\left.35), 36), 37), 39), 40), 46), 47)^{*}, 48\right)^{*}, 50\right), 52\right), 54\right), 55\right), 60\right), 61\right), 73\right)$, 75), 76), 77), 81), 82), 83) $\left.\left.\left.{ }^{* 2}, 84\right), 85\right), 86\right), 87$ )

0 uncertain differences

5 partial differences: 25), 28), 29), 45), 78)

$*_{1}$ The difference of the different 3 rd p. sg. masc. pron. suffix in 47) and 48 ) is already covered in MAP 34 .

$*_{2}$ The difference is in raising of $a$ ('alēh > ilēh in 83 ), which is already covered in MAP 76 ).

Total 34,5 differences; percentage of corrected total $(=95) 36.3 \%$

-29- Isogloss bundle $\mathrm{nr}-29$ - distinguishes GrA from MzA.

24 (minus $2^{*}$ ) differences: 4$\left.\left.\left.\left.\left.\left.\left.\left.\left.), 7\right), 8\right), 11\right), 14\right), 18\right), 20\right), 26\right), 31\right), 48\right), 5^{2}$ ), $\left.57), 58), 61), 62), 68), 71), 78), 79), 80), 82), 84)^{*}, 85\right)^{*}, 86$ )

0 uncertain differences

9 partial differences: 16), 25), 27), 28), 29), 39), 40), 42), 81)

* The difference here is mainly in stress, which is already covered in MAP 14.

Total 26,5 differences; percentage of corrected total (= 95) $27.9 \%$ 
-30- Isogloss bundle $\mathrm{nr}-30-$ distinguishes GrA from ǦbA.

1 difference: 79 )

o uncertain differences

7 partial differences: 29), 31) $\left.\left.\left.\left.{ }^{*}, 39\right), 40\right), 61\right), 82\right), 85$ )

* The difference is in frequency of occurrence of the forms discussed, therefore the difference is here concluded to be partial.

Total 4,5 differences; percentage of corrected total (= 95) 4.7\%

-31- Isogloss bundle $\mathrm{nr}-3^{1-}$ distinguishes ĞbA from MzA.

21 (minus $2 *^{*} *_{3}$ ) differences: 4), 7), 8), 11), 14), 18), 20), 26), 31) $\left.{ }^{*_{1}}, 48\right)$,

$\left.\left.\left.\left.\left.\left.\left.\left.\left.\left.5^{2}\right), 57\right), 5^{8}\right), 62\right), 68\right), 71\right), 78\right), 79\right), 80\right), 84\right)^{* 3}, 86$ )

0 uncertain differences

9 partial differences: 16), 25), 27), 28), 42), 61) $\left.\left.\left.{ }^{*_{2}}, 81\right), 82\right), 85\right)^{*_{2}}$

$*_{1}$ The difference is in frequency of occurrence of the forms discussed, but the difference is greater than in bundle $-30-$, therefore the difference is here not concluded to be partial.

$*_{2}$ The difference here is partly in stress, which is already covered in MAP 14.

$*_{3}$ The difference here is mainly in stress, which is already covered in MAP 14.

Total 23.5 differences; percentage of corrected total (= 95) $24.7 \%$

-32- Isogloss bundle $\mathrm{nr}-\mathbf{3}^{2-}$ distinguishes BWA from GrA.

27 differences: 4), 7), 8), 11), 14), 18), 20), 22), 26), 37), 39), 40), 46), $\left.\left.\left.\left.\left.\left.\left.\left.\left.\left.\left.\left.48), 5^{2}\right), 57\right), 58\right), 61\right), 62\right), 68\right), 71\right), 78\right), 80\right), 83\right), 84\right), 85\right), 86$ )

0 uncertain differences

10 partial differences: 10), 25), 29), 31) $\left.\left.\left.\left.\left.\left.{ }^{* 1}, 42\right), 73\right), 75\right), 77\right), 79\right)^{* 2}, 81\right), 82$ )

$*_{1}$ The difference is in frequency of occurrence of the forms discussed, therefore the difference is here concluded to be partial.

$*_{2}$ The difference is only in the negated 2 nd p. sg. masc. pronominal, therefore a partial difference is concluded.

Total 32 differences; percentage of corrected total (= 95) 33.7\%

-33- Isogloss bundle $\mathrm{nr}-33^{-}$distinguishes BWA from ĞbA.

27 differences: 4$\left.\left.\left.), 7), 8), 11), 14), 18), 20), 22), 26), 31)^{*}, 37\right), 46\right), 48\right)$, $\left.\left.\left.\left.\left.\left.\left.\left.\left.\left.\left.\left.\left.5^{2}\right), 57\right), 58\right), 61\right), 62\right), 68\right), 71\right), 78\right), 80\right), 82\right), 83\right), 84\right), 85\right), 86$ ) 
o uncertain differences

12 partial differences: 10), 25), 39), 40), 42), 49), 73), 75), 77), 79), $80), 81$ )

* The difference is in frequency of occurrence of the forms discussed, the difference is here concluded to be not partial, (contrast remark * below in $-34^{-}$).

Total 33 differences; percentage of corrected total (= 95) 34.7\%

-34- Isogloss bundle $\mathrm{nr}-34-$ distinguishes ASA from BwA. 26 differences: 4), 7), 8), 11), 14), 18), 20), 22), 26), 37), 46), 48), 52), 57), 61), 62), 63), 71), 78), 79), 80, 82), 83), 84), 85), 86) o uncertain differences 11 partial differences: 10), 25), 31) $\left.\left.\left.\left.\left.\left.\left.)^{*}, 39\right), 40\right), 42\right), 58\right), 73\right), 75\right), 77\right), 81$ )

* The difference is in frequency of occurrence of the forms discussed, therefore the difference is here concluded to be partial.

Total 31.5 differences; percentage of corrected total $(=95) 33.2 \%$

-35- Isogloss bundle $\mathrm{nr}-35^{-}$distinguishes ASA and ĞbA.

1 difference: 22 )

o uncertain differences

7 partial differences: 31$\left.\left.\left.\left.\left.)^{*}, 46\right), 58\right), 61\right), 79\right), 82\right), 85$ )

* The difference is in frequency of occurrence of the forms discussed, therefore the difference is here concluded to be partial.

Total 4.5 differences; percentage of corrected total $(=95)$ 4.7\%

-36- Isogloss bundle $\mathrm{nr}-36$ - distinguishes ASA from HnA.

2 differences: 21$), 48$ )

0 uncertain differences

3 partial differences: 45), 58), 71)

Total 3.5 differences; percentage of corrected total $(=95) 3.7 \%$

-37- Isogloss bundle $\mathrm{nr}-37$ - distinguishes ASA from MzA. 23 (minus $3^{*_{2}}$ ) differences: 4 ), 7), 8), 11), 14), 18), 20), 22), 26), 48), 52), $\left.\left.\left.\left.\left.\left.\left.\left.\left.\left.57), 61)^{* 2}, 62\right), 68\right), 71\right), 78\right), 79\right), 80\right), 82\right), 84\right)^{* 2}, 85\right)^{* 2}, 86\right)$

o uncertain differences 
10 partial differences: 16$\left.\left.\left.\left.), 25), 27), 28), 31)^{*_{1}}, 42\right), 45\right), 46\right), 58\right), 81$

$*_{1}$ The difference is in frequency of occurrence of the forms discussed, therefore the difference is here concluded to be partial.

$*_{2}$ The difference here is in stress, which is already covered in MAP 14 .

Total 25 differences; percentage of corrected total (= 95) $26.3 \%$

-38- Isogloss bundle $\mathrm{nr}-38$ - distinguishes ḤmA from ȘwA.

7 differences: 20), 47), 48), 60), 71), 81), 85)

o uncertain differences

13 partial differences: 7), 18), 25), 31)*, 37), 50), 54), 58), 68), 79), 83), 84), 86)

* The difference is in frequency of occurrence of the forms discussed, therefore the difference is here concluded to be partial.

Total 13.5 differences; percentage of corrected total (= 95) 14.2\%

Finally, to have an idea of the typological distance between the dialects of the Mzēnah and the Baniy Wāșil, ${ }^{10}$ we compare these dialects on the basis of the same criteria:

-39- Isogloss bundle $\mathrm{nr}-39$ - is 'virtual' and distinguishes BWA from MzA.

9 differences: 37), 39), 40), 46), 79), 82), 83), 84), 85)

0 uncertain differences

9 partial differences: 10), 16), 22), 27), 28), 73), 75), 77), 81)

Total 13.5 differences; percentage of corrected total (= 95) 14.2\%

\section{b. The Step Method to Calculate Relative Typological Distances between Dialects}

The comparisons are made using a total of 95 criteria (73 in maps in De Jong 2000, criteria A, B, C, D, E, F, G, H, and I (see De Jong 2000:37-38)

${ }^{10}$ Since the Awlād Sa îd (who live more inland in the high mountains towards the east than indicated on the map, see fn 1, p. 115) are not physically located between the two dīrahs of the Mzēnah and Baniy Wāșil, the dīrahs of the latter two tribes in actual fact border on each other. 
and 13 criteria represented by maps $75^{-87}$ added in the appendix of this volume):

Score card:

Below the isogloss bundles between dialects have been ranked from low to high.

\begin{tabular}{|c|c|c|c|c|c|c|}
\hline \multirow{2}{*}{$\begin{array}{c}\begin{array}{c}\text { isogloss } \\
\text { bundle } \\
\text { number }\end{array} \\
-3^{6-}\end{array}$} & \multirow{2}{*}{$\begin{array}{c}\begin{array}{c}\text { between } \\
\text { dialects }\end{array} \\
\text { (ASA-HnA) }\end{array}$} & \multirow{2}{*}{$\begin{array}{c}\text { of groups } \\
\text { VII-VII }\end{array}$} & \multirow{2}{*}{$\begin{array}{c}\begin{array}{c}\text { number of } \\
\text { isoglosses } \\
\text { of total incl } \\
\text { uncertain }\end{array} \\
3.5\end{array}$} & \multicolumn{2}{|c|}{$\begin{array}{l}\text { subtract from } 95 \text { for } \\
\text { uncertain }\end{array}$} & \multirow{2}{*}{$\begin{array}{c}\begin{array}{c}\text { percentage } \\
\text { of corrected } \\
\text { total }\end{array} \\
3.7 \%\end{array}$} \\
\hline & & & & & $(3.5 / 95)$ & \\
\hline$-26-$ & $($ ȘwA-GrA) & VII-VII & 3.5 & & $(3.5 / 95)$ & $3.7 \%$ \\
\hline$-35^{-}$ & (ASA-ǦbA) & VII-VII & 4.5 & & $(4.5 / 95)$ & $4.7 \%$ \\
\hline$-30-$ & (GrA-ǦbA) & VII-VII & 4.5 & & $(4.5 / 95)$ & $4.7 \%$ \\
\hline$-2-$ & (MlA-nTA) & I-I & 10 & 11 & $(4.5 / 84)$ & $5.4 \%$ \\
\hline$-10-$ & (DbA-TyA) & $\mathrm{I}-\mathrm{I}$ & 6.5 & & $(6.5 / 95)$ & $6.8 \%$ \\
\hline$-1-$ & (SA-MlA) & $\mathrm{I}-\mathrm{I}$ & 10 & 7 & $(6.5 / 88)$ & $7 \cdot 4 \%$ \\
\hline$-4^{-}$ & ('AyA-AhA) & I-I & 11.5 & 9 & $(7 / 86)$ & $8.1 \%$ \\
\hline$-3^{-}$ & (nTA-TyA) & I-I & 13.5 & 9 & $(8 / 86)$ & $8.1 \%$ \\
\hline$-18-$ & (BdA-TyA) & $\mathrm{I}-\mathrm{I}$ & 8.5 & & $(8.5 / 95)$ & $8.9 \%$ \\
\hline$-21-$ & (TyA-TAN) & $\mathrm{I}-\mathrm{I}$ & 9 & & $(9 / 95)$ & $9.5 \%$ \\
\hline$-8-$ & (TyA-AhA) & $\mathrm{I}-\mathrm{I}$ & 10 & 2 & $(9 / 93)$ & $9.7 \%$ \\
\hline$-9^{-}$ & (Aha-DbA) & $\mathrm{I}-\mathrm{I}$ & 10 & 3 & $(9 / 93)$ & $9.7 \%$ \\
\hline$-5^{-}$ & ('AyA-HwA) & $\mathrm{I}-\mathrm{I}$ & 13.5 & 10 & $(8.5 / 85)$ & $10 \%$ \\
\hline$-12-$ & (ǦrA-Ḥ̂) & I-I & 9.5 & & $(9.5 / 95)$ & $10 \%$ \\
\hline$-22-$ & ('LA-ḤmA) & VIII-VII & 10 & & $(10 / 95)$ & $10.5 \%$ \\
\hline$-15^{-}$ & (HwA-TyA) & I-I & 10 & & $(10 / 95)$ & $10.5 \%$ \\
\hline$-11-$ & (TAȘ-ĞrA) & $\mathrm{I}-\mathrm{I}$ & 10.5 & & $(10.5 / 95)$ & $11 \%$ \\
\hline$-6-$ & (HwA-AhA) & $\mathrm{I}-\mathrm{I}$ & 10.5 & 1 & $(10.5 / 94)$ & $11.1 \%$ \\
\hline$-17-$ & (HwA-BdA) & $\mathrm{I}-\mathrm{I}$ & 11 & & $(11 / 95)$ & $11.6 \%$ \\
\hline$-19^{-}$ & (AhA-TAN) & I-I & 11 & 1 & $(11 / 94)$ & $11.7 \%$ \\
\hline$-39^{-*}$ & (BWA-MzA) & VI-VI & 13.5 & & $(13.5 / 95)$ & $14.2 \%$ \\
\hline$-38-$ & (ḤmA-ȘwA) & VII-VII & 13.5 & & $(13.5 / 95)$ & $14.2 \%$ \\
\hline$-23^{-}$ & ('LA-ȘwA) & VIII-VII & 15 & & $(15 / 95)$ & $15.8 \%$ \\
\hline$-7-$ & (HwA-TAȘ) & I-I & $15 \cdot 5$ & & $(15.5 / 95)$ & $16.3 \%$ \\
\hline$-25^{-}$ & ('LA-GrA) & VIII-VII & 16 & & $(16 / 95)$ & $16.8 \%$ \\
\hline$-31^{-}$ & (ǦbA-MzA) & VII-VI & 23.5 & & $(23.5 / 95)$ & $24.7 \%$ \\
\hline$-37^{-}$ & (MzA-ASA) & VI-VII & 25 & & $(25 / 95)$ & $26.3 \%$ \\
\hline$-29-$ & (GrA-MzA) & VII-VI & 26.5 & & $(26.5 / 95)$ & $27.9 \%$ \\
\hline$-27-$ & (ṢwA-MzA) & VII-VI & 27 & & $(27 / 95)$ & $28.4 \%$ \\
\hline
\end{tabular}


Table (cont.)

\begin{tabular}{|c|c|c|c|c|c|}
\hline $\begin{array}{l}\text { isogloss } \\
\text { bundle } \\
\text { number }\end{array}$ & $\begin{array}{c}\text { between } \\
\text { dialects }\end{array}$ & of groups & $\begin{array}{c}\text { number of } \\
\text { isoglosses } \\
\text { of total incl } \\
\text { uncertain }\end{array}$ & $\begin{array}{l}\text { subtract from } 95 \text { for } \\
\text { uncertain }\end{array}$ & $\begin{array}{l}\text { percentage } \\
\text { of corrected } \\
\text { total }\end{array}$ \\
\hline$-34-$ & (ASA-BWA) & VII-VI & 31.5 & $(31.5 / 95)$ & $33.2 \%$ \\
\hline$-32-$ & (BWA-GrA) & VI-VII & 32 & $(32 / 95)$ & $33 \cdot 7 \%$ \\
\hline$-33^{-}$ & (BWA-ǦbA) & VI-VII & 33 & $(32 / 95)$ & $34.7 \%$ \\
\hline$-28-$ & (MzA-TAN) & VI-I & 34.5 & $(34.5 / 95)$ & $36.3 \%$ \\
\hline$-14-$ & (ĞrA-'LA) & I-VIII & 35 & $(35 / 95)$ & $36.8 \%$ \\
\hline$-13^{-}$ & (TAȘ-LA) & I-VIII & 37.5 & $(37.5 / 95)$ & $39.5 \%$ \\
\hline$-20-$ & ('LA-BdA) & VIII-I & 41.5 & $(41.5 / 95)$ & $43.7 \%$ \\
\hline$-16-$ & ('LA-HwA) & VIII-I & 42 & $(42 / 95)$ & $44.2 \%$ \\
\hline$-24-$ & (BdA-Ṣw) & I-VII & 45.5 & $(45 \cdot 5 / 95)$ & $47.9 \%$ \\
\hline
\end{tabular}

* isogloss bundle - 39 - is 'virtual' in the map (but 'real' on the ground), see remarks above and in fn 1, p. 115 .

Our figured calculations using the step method show a few results that do not appear to be in concord with earlier results in De Jong 2000: the subdivision into groups is not as clear-cut here in terms of percentages as it was in De Jong 2000. The reason appears to be that in De Jong 2000 we were looking at dialects that form a geographical continuum, which makes the comparison between the groups largely uni-directional (i.e. east-west or west-east, depending on preference).

Our dialects in the centre and south of Sinai do not form a comparable continuum, which makes the comparison between more than two groups (I, VI, VII and VIII) multi-directional. Such a garbled picture is also the result of a comparison between dialects of tribes that-even within certain identified groups-have arrived at different times and have over these different periods of time influenced each other to a lesser or greater degree. In addition, the comparison is between dialects of tribes, who can vary greatly with regard to numbers of members.

To give an example: the tribe Hamāḍah is considerably smaller (in terms of numbers of members) than the neighbouring tribes of 'Lēgāt and Șawālḥah. ḤmA still shows a number of features which are reminiscent of the group I-type, and presumably this dialect type is much nearer to the original HmA-type than the group to which it has now been assigned (i.e. group VII). 
The reason to assign $\mathrm{HmA}$ to group VII is that $\mathrm{HmA}$ can be concluded to be developing into the direction of this group; 'originally' group I features are being replaced by group VII features, as is to be concluded from the variation that occurs. For this reason, HmA and 'LA have been assigned to different groups, even though the MDS plots and the step method both show relative typological proximity. The choice to isolate 'LA as a group by itself is thus partly subjectively inspired, and it is not being fully illustrated by the quantifying methods applied here. The only exception is the dendrogram (see p. 375 in the appendix), where 'LA is clearly branched separately, although inside group VI, for instance, the two dialects assigned to the same group (MzA and BWA) branch at exactly the same height. The subjective argument for the decision to nevertheless assign 'LA to a separate group is in the type of characteristics that distinguish 'LA from HmA (see next paragraph). In any case, $\mathrm{HmA}$ is not a proto-typical representative of group VII."

\section{c. A Continuum: From Group VII Through Group VIII Towards Group I}

One may conclude a continuum (albeit on a much smaller scale than the situation on the northern littoral), which is best illustrated in the Alscal (Euclidean Binary, see p. 374) MDS plot: from the typically southern dialect type of group VII ( $\mathrm{HmA}$ is here excluded from VII for not being prototypical, see remark in the preceding paragraph), the continuum moves through HmA, via 'LA to group I, for although there is always the question of relative 'typological weight', some differences in features set as criteria in a comparison tend to be more illustrative than differences found in other features, especially when seen in combination with features present in other groups. One could say that in this sense, although 'LA and HmA show relatively few differences, in cases where they do, 'LA tends to 'lean towards' group I, while HimA tends to 'lean towards' group VII.

To give an example: in 2.1.1.2.1. some imperative forms present in TwA and 'LA are cited. We see here that 'LA leans towards group I with its imperative forms kul, gūl, gūm, šul and nām (without a stressed initial vowel), whereas ȚwA dialects generally do show such vowels, e.g. (TwA) úkul "eat!", úgum "stand up!", išil "carry!" and ánam "go to sleep!".

"To cite a parallel with biology: if we were to discuss 'birds' in general, we would probably choose to be talking about proto-typical examples like a sparrow, a robin or a canary, rather than an ostridge or a penguin, see Aitchison 1987:51-62. 
Another example is the difference between velarization in the pl. forms of kibir and kitīir (kbār and ktǟr in 'LA), but lack of velarization in both forms in TwA ( $k b \overline{\ddot{a} r}$ and $k \underline{\underline{a}} \overline{\ddot{r}}$ ), and 'LA thus takes up an intermediate position between groups VII and I (the latter having $k b \bar{a} r$ and $k \underline{t} \bar{a} r$ ).

Another illustration of 'LA occupying such an intermediate position between groups VII and I is placement of stress in CvCvC (see 3.2.2.4.1. and 3.2.2.4.2.). Group I dialects surrounding ' $\mathrm{LA}$ all have CaCáC or CiCíC, while group VII will stress CáCaC and CíCiC, but in 'LA both possibilities exist as parallel options. This shows that the situation in HmA is in these respects more in conformity with the situation in (other) group VII dialects, than it is with the situation in 'LA, or even group I for that matter. The situation in 'LA would then be an indication of influences from surrounding group I dialects, if it is not an original feature of 'LA itself.

There is also the example of a stressable article in the sequence alCa$\mathrm{CaC}$ (see 2.1.1.): in 'LA, like in group $\mathrm{I}$, álCaCaC is the rule, whereas in group VII (excluding HmA) ilCáCaC is regular. HmA takes up an intermediate position here, allowing both possibilities as parallel options.

If we combine stressability of the vowel of the article with stress in the perfect on the initial vowel of the $n-1$ and $1-t$ measures of verbs (see 1.2.3.4.3.2., 3.2.3.1.1. and 3.2.3.3.1.), we see that group I will stress both (e.g. álbaṣal and ánwakal), group VII will stress neither (in group VII ilbáșal and inwákal), while 'LA will stress the article, but not the initial vowel in preformatives of the perfect of $n$-1 or 1-t measures (álbașal, but inwákal and ittáfag).

In the negation of verb forms (see 4.2.), we see that 'LA uses the single $m \bar{a}+$ verb form, which is like the situation in group I. TwA dialects other than HmA will use compound $m \bar{a} / m a+$ verb form $+-s(i)$. HmA in this case takes up the intermediate position allowing both possibilities as parallel options (without any apparent differences in meaning, such as is the case in some dialects where the single negation with $m \bar{a}$ is used when extra emphasis is intended).

Finally, both 'LA and HmA take up an intermediate position between groups VII and I in the allomorphs of the 2nd p. sg. fem. pronominal suffix (see 3.1.12.2.); where group I has invariable -kiy and group VII has $\overline{\mathrm{v}}-k$, vC- $k$ or CC-ik, both 'LA and HmA have $-i k$ when not directly preceded by $\overline{\mathrm{V}}$, but -kiy when $\overline{\mathrm{v}}$ directly precedes (i.e. a situation comparable to the allomorphs current in Cairene Arabic, where we have similarly conditioned appearance of allomorphs $-i k$ and $-k i){ }^{12}$

${ }^{12}$ Cf. Woidich 2006:40. 
Although both 'LA and HmA seem to take up an intermediate position between group VII and group I, I have chosen to group 'LA separately as group VIII, because the 2-dimensional MDS plots clearly position it between groups VII and I, while HmA is plotted considerably nearer to other group VII dialects, and is thus concluded to be more part of group VII than of group VIII. The dendrogram in the appendix illustrates the same.

In a similar manner the dialect of Baniy Wāșil has been developing from a presumed 'originally's group I-type towards the dialect-type of the Mzēnah. The assumption of BwA originally being a group I type of dialect appears to be supported by BWA's position on the Alscal Euclidean Binary MDS plot (see p. 374); of all dialects of groups VI, VII and VIII (spoken in the south of Sinai) BWA is located nearest to group I.

If we compare the results of the step method with the multi-dimensional scaling (MDS-) plots produced by Proxscal and Alscal in SPSS we see that these MDS plots provide a better overall picture of the total area.

\section{d. Multi-Dimensional Scaling}

In some cases 'virtual isoglosses' were introduced in the 'step method' to show relative typological distance between dialects that do not geographically directly border on each other-or only seemingly so, as is the case with MzA and BWA.

Since the Proxscal and Alscal programmes (a matrix in the SPSS used for the MDS method) compare all dialects on the basis of the same criteria, all such relative typological distances-also of dialects that do not border on each other and may geographically even be far removed from each other-will receive a graphic representation in the MDS plot generated (see figure 3 in the appendix for the colour version of this plot).

The advantage of this MDS approach over the step method is that relative proximity/distance of every dialect in relation to every other dialect in a larger geographical area is calculated, which is then represented in a plot. Especially in societies with collectives of individuals who are, or were until recently, inherently spatially dynamic (such as a society with (semi-) nomadic tribes), relative typological proximity of dialects that do not geographically directly border on each other is potentially more

${ }^{13}$ As I was told by several speakers of surrounding dialects. This is also supported by features (which are also present as parallel to other features in the dialect) still present in BWA. For features that BWA (but not MzA) has in common with group I, see the list in Conclusions, III. g. below. See also remark in fn 5, p. 117 in this volume. 
revealing than the same method being applied in inherently spatially static societies (such as is often the case with centuries old villages/towns, rural communities etc. in a more typically non-nomadic context, like for instance in Europe).

In nomadic societies-much more so than in a European contextsocial collectives like (even if they are only semi-nomadic) tribes travel around, and since much of dialect change originates from contact with speakers of other dialects, influences of dialects of speakers, that today geographically border on these collectives, may have been effective and thus mask an older version of the dialect of that same collective. However, proper interpretation of existing variation may provide insight into earlier stages of such a dialect, at least during the stages in which variation exists, and even after focussing has resulted in the disappearence of parallel forms, interdialect forms may provide such clues. ${ }^{14}$

An example to cite here is the parallel existence of ${ }^{u} k$ and $-a k$ pronominal suffixes for the 2nd p. sg. masc. in the dialect of older speakers of group II in the north. ${ }^{15}$ If we can take the older speaker's word for it—and

Object Points

Common Space

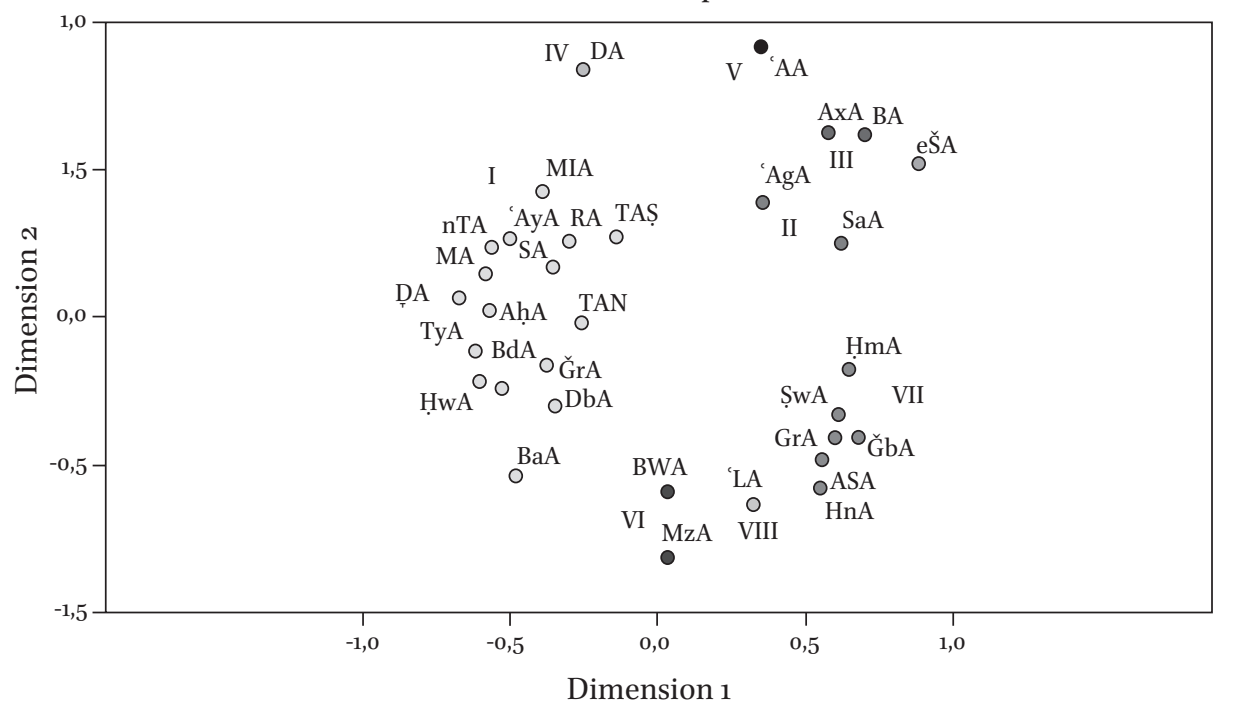

Proxscal-Euclidian Binary MDS plot of dialects of Sinai

${ }^{14}$ See Trudgill 1983:chapter 5 and also Woidich 1997.

${ }^{15}$ See De Jong 2000:288. 
I saw no reason to doubt him-the Samānnah lived in the area of aț-Tūr until the turn of the 19th-2oth century. Since dialects there all have $-{ }^{u} k$, a logical assumption would be that SaA too had ${ }^{u} k$ at the time they moved to the Gatyah oasis in the north. There they came into contact with speakers of Axrasiy (AxA) and Biyyādiy (BA), which resulted in the -ak suffix being introduced to speakers of $S a A .{ }^{16}$ The velarization present in the form $-{ }^{u} k$ was then transferred onto the $k$ of the $-a k$ suffix, resulting in the 'interdialect' form $-a k$. When both ${ }^{~}{ }^{k} k$ and were $-a k$ were used as parallel forms, "focussing" took place which produced -ak as the preferred form, while $-{ }^{-} k$ is (was?) only being used by older men ${ }^{17}$ and may thus be expected to eventually result in the disappearance of the latter form.

\section{e. 'Bedouinness'vs 'Sedentariness'}

In De Jong 2000:37-47 a total of 41 features are listed as criteria to establish relative 'bedouinness' or 'sedentariness' of dialects. These features are marked as 'B-S criteria' (these are also marked as such in the list in 'Conclusions II. a. Criteria for comparison from De Jong 2000 producing differences/similarities in central and southern Sinai' above). These B-S criteria are listed here with comments on the score of the three typological groups (VI, VII and VIII) discussed in the volume in hand (the numbering used is in reference to the list in De Jong 2000) (For B-S features used as criteria for comparison numbered from A) to L), see "II.a. Criteria for comparison from De Jong 2000 producing differences/similarities in central and southern Sinai" above):

2. All four groups (I, VI, VII and VIII) show interdental reflexes $\underline{t}$ for ${ }^{*} \underline{t}$ and $\underline{d}$ for * $\underline{d}$.

All dialects in central and southern Sinai score 1.

3. All four groups (I, VI, VII and VIII) show emphatic interdental $\underset{d}{d}$ for merged ${ }^{*} \underset{\sim}{d}$ and ${ }^{*} \underset{\text { en }}{ }$.

All dialects in central and southern Sinai score 1.

4. Secondary velarization: group I dialects in the centre (like in other group I dialects) show velarization in both $k b \bar{a} r$ and $k t a \bar{a} r$, groups VI and VIII only have velarization in $k b \bar{a} r$, but not in $k \underline{\underline{a}} \bar{a} r$, and group VII lacks velarization in both forms: $k b \bar{a} r$ and $k \underline{t} \ddot{a} r$.

\footnotetext{
${ }^{16}$ In some schools in the Gatyah oasis children from different tribes mix.

${ }^{17}$ And perhaps also by women, but there are no recordings of women speakers of this tribe to verify this.
} 
Score group I: 1; group VI: 0.5; group VII: 0 ; and group VIII: 0.5 .

6. All dialects have a tendency to retain length of long vowels in unstressed positions.

All dialects in central and southern Sinai score 1.

7. In all groups $a$ in open syllable preceding A (stressed $a$ or $\bar{a}$ ) is raised.

All dialects in central and southern Sinai score 1.

9. In group I dialects extreme raising of final * $-\bar{a}\left({ }^{\prime}\right)$ in neutral surroundings is current. In groups VI, VII and VIII final ${ }^{*}-\bar{a}$ is raised in a similar manner, but final $-\vec{a}$ tends to be reflected as $-i$.

Group I scores 1, groups VI, VII and VIII score 0.5 .

17. None of the dialects in the centre and south of Sinai show resyllabication of $\mathrm{CaCaCv}$ sequences.

All dialects in central and southern Sinai score 0.

18. In groups I and VI the definite article and preformatives of verbal measures $n-1$ and 1-t are stressable units (e.g. álwalad, ándarab, áttafag). In group VII the article is not stressed (e.g. ilwálad), although in HmA both stress-types are used (e.g. álwalad ilwálad). In group VIII the article is also a stressable unit (e.g. álwalad).

Preformatives of the perfect forms of measures $n-1$ and 1- $t$ are not stressed in groups VII and VIII (e.g. inḍárab, ittáfag).

Group I scores 1; group VI scores 1; group VII scores o (but HmA scores 0.25); group VIII scores 0.5 .

19. All dialects have an active gahawah-syndrome.

All dialects in central and southern Sinai score $\mathbf{1 .}$

20. Presence of initial CC in a limited number of morphological patterns:

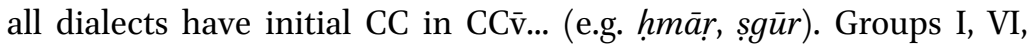
VIII and also ḦmA and (part of) ĞbA of group VII have initial CC in CCv ... (e.g. 'nab "grapes", grab "watersacks"). Other group VII dialects have however morphologically resolved the initial cluster in this pattern with an initial vowel (e.g. ánab, ágrab).

Groups I, VI, VIII and ḦmA and ĞbA of VII score 1. Other dialects of group VII score 0.5 .

25. The initial vowel in the definite article and the relative pronoun: $a$ in group I (al- and alliy). In group VI and HmA of group VII $a l-\sim i l-$ and illiy. In group VII il- and illiy. In group VIII il- $\sim$ al- and alliy.

Group I scores 1. Group VI and HmA score 0.5, Group VII scores 0. Group VIII scores 0.5 .

30. All dialects have gender distinction in the 2 nd and 3 rd p. pl. of personal pronouns, adjectives and verbs. 
All dialects in central and southern Sinai score 1.

34. Shape of the personal pronominal suffix for the third p. sg. masc.: $-a h$ or -ih in group I. Groups VI, VII and VIII all have $-u(h)$.

Group I scores 1. Groups VI, VII and VIII score 0.

39. Emphatization of $\underline{d}$ in demonstratives $h \bar{a} \underline{d}+$, if not followed by $i$. Group I has $h \bar{a} \underline{d} a \sim h \bar{a} \underline{d} a$ (with the exception of HwA, where only $h \bar{a} \underline{d} a$ was heard). In groups VI, VII and VIII such velarization of $\underline{d}$ in this position is absent.

Group I scores 1. HwA, groups VI, VII and VIII score 0.

41. Gender distinction in pl. demonstratives: dialects in central and southern Sinai use pl. com. forms for pl. masc. and fem. (in MzA a pl. form used for the fem. was recorded, but the com. form was more current). All dialects in central and southern Sinai score o, except MzA, which scores 0.5 .

42. All dialects of group I have a short vowel in the interrogative min "who?". Groups VI, VII and VIII have a long vowel in min.

Group I scores 1. Other dialects in central and southern Sinai score 0.

43. Initial consonant in the interrogative for "where?": all dialects of central and southern Sinai have initial $w$ in wēn.

All dialects in central and southern Sinai score 1.

44. Interrogative for "how": all dialects have kêf or kîf.

All dialects in central and southern Sinai score 1.

45. Adverb for "there": group I has hnuh. Group VI has hnuh hnōtiy or hnütiy, groups VII and VIII have hnōtiy or hnütiy. In all dialects the occasional K-form hnäk can be heard.

All dialects in central and southern Sinai score $1 .^{18}$

46. Adverb for "here": group I and BWA have hniy (or hniyyih, and in the central eastern Sinai hniyyān(iy)), groups VII and VIII and MzA have niha $\left({ }^{\prime}\right) \sim$ nihāniy. In all dialects the K-form hina (often in its adapted shape as hinih or hiniy).

All dialects in central and southern Sinai score $1 .^{19}$

47. Preposition $l+$ vowel-initial suffix: group I has lah or lih. Groups VI, VII and VIII have luh.

All dialects in central and southern Sinai score 1 (see remarks on the suffixes $-u h$ or $-a h$ / -ih below).

\footnotetext{
${ }^{18}$ Since the true 'sedentary' form (i.e. a form used in the Nile Delta and Cairo) is $h(i) n \bar{a} k$, I regard hnōtiy or hnütiy as 'Bedouin' in this context.

${ }_{19}$ Since the true 'sedentary' form (i.e. a form used in the Nile Delta and Cairo) is hina, I regard nihä(') or nihāniy as 'Bedouin' in this context.
} 
53. Vowel harmony in the imperfect prefix of verbal measure 1: yašrab, yiktib, yug'ud. All dialects in central and southern Sinai show such harmonized vowels.

All dialects in central and southern Sinai score 1.

56. Imperfect of primae $w \bar{a} w$ verbs: none of the Bedouin dialects of central and southern Sinai have a morphologically patterned diphthong $i w$. Forms are more typically yawșal or yōṣal "he arrives", and sometimes the $w \bar{a} w$ is dropped from the stem, like in talid "she gives birth".

All dialects in central and southern Sinai score 1.

65. Use of measure 4 verbs: all dialects use measure 4 verbs relatively frequently.

All dialects in central and southern Sinai score 1.

66. Typical "Bedouin" verb-type with inserted wāw, e.g. sōlaf, ysōlif "tell". In all dialects of central and southern Sinai this verb-type is current. All dialects in central and southern Sinai score 1.

67. The sg. fem. active participle + object suffix: in all dialects of central and southern Sinai a construct state is current.

All dialects in central and southern Sinai score 1.

68. Shape of the verbal negation: $m \bar{a}+$ verb or $m a+\operatorname{verb}+\check{s}(i)$. Group I, 'LA (group VIII) and BWA (of group VI) use the singular negation ( $m \bar{a}$ + verb form) almost exclusively. MzA (of group VI) uses both types of negation, and in group VII the compound negation is current $(m a+$ verb $+-\check{s})$.

Groups I, VIII ('LA) and BWA (of group VI) score 1. MzA (of group VI) scores 0.5 . Group VII scores 0.

69. The $b$-imperfect: in all dialects of central and southern Sinai the $b$-imperfect is current.

All dialects in central and southern Sinai score 0.

71. Use of $y \bar{o} m($ in $)$ or $\operatorname{lōm}$ (in) for "when". In all dialects yōm(in) or $\operatorname{lom}$ (in) is current.

All dialects in central and southern Sinai score 1.

73. Use of widd or bidd to express "want; need": group I uses widd. BWA (of group VI) and HmA (of group VII) use both. The other dialects of group VII, group VIII and MzA (of group VI) use bidd.

Group I scores 1. BWA (of group VI) and HimA (of group VII) score 0.5 . MzA, dialects of group VII (except H.MA) and group VIII ('LA) score o.

When we count the 'Bedouin' features of dialects of the 30 listed here by adding up the 'scores' in the list above, we see the following in the totals: 
Group I scores highest ${ }^{20}$ with almost all dialects having 27 features as 'Bedouin'. Dialects of group VII score 18.5, except the dialect of the Hamāḍah, which scores 19.75 'Bedouin' features. The dialect of the 'Lēgāt (group VIII) scores 21 'Bedouin' features.

Although the dialects of groups VI, VII and VIII score less on Bedouin features (for the Negev dialect) than the group I dialects, if we compare the scores of VI, VII and VIII to scores of the dialects of the Biyyādiyyah and Axārsah in the north, we see that the dialects of groups VI, VII and VIII in the south still score considerably higher on Bedouin features than BA (scoring 8) and AxA (scoring 9). ${ }^{21}$

In reference to criteria listed above in 'Conclusions II. a. Criteria for comparison from De Jong 2000 producing differences/similarities in central and southern Sinai', the following remarks must be taken into account:

There may be reasons that certain typological differences between dialects in the central and southern area of Sinai are indeed also to be interpreted as forming part of a greater 'development' of dialects away from the Bedouin type towards a more sedentary type, but in this central and southern area of Sinai a direct and explicit geographical dimension-like the east-west dimension reflecting the 'Bedouin-less Bedouin' dimension in the north of Sinai ${ }^{22}$-is lacking. If certain differences are to be attributed at all to dialect contact of 'Bedouin' dialects with the more sedentary type, we would need to know more first of all about the dialects of related (sub-) groups of tribes in other areas such as the related tribal collectives (in many cases with identical names) in present-day Saudi Arabia or Jordan.

Secondly, we would need more historical data on the movement of tribes, or smaller collectives such as families, should we wish to measure with some acceptable accuracy the as yet unquantified influence on Bedouin dialects of speakers of sedentary dialects. To give an example: one

${ }^{20}$ This is not surprising, since the list was compiled to specifically illustrate the relative 'Bedouinness' of dialects in the north of Sinai as compared to the dialect of the Dullām in the Negev, which all belong to the same group I.

${ }^{21}$ BA and AxA are cited here as the clearest examples inside Sinai of Bedouin dialects which have acquired sedentary features through influence of dialect contact with sedentary dialects of the Nile Delta, see De Jong 2000:622-627. The numbers 7 and 8 cited here are the result of a count not made in De Jong 2000, but made here for the purpose of comparing groups VI, VII and VIII to group III in the north. Data on BA and AxA are in De Jong 2000:Chapter III.

${ }^{22}$ See remarks on this east-west dimension in the north of Sinai in De Jong 2000:622-627. 
could assume the personal pronominal suffix of the 3 rd p. sg. masc. $-a h$ or -ih to be representative of the 'Bedouin' type, and thus conclude the -uh suffix (like that recorded in the dialect of the Mzēnah of Sinai) to be more 'sedentary' (because it is identical with the $-u$ pronominal suffix found in the Nile Delta), but at the same time we do know that in many Bedouin dialects of the Arabian Peninsula - where influence of sedentary dialects, in any case of those spoken in the Nile Delta or Cairo, is highly unlikely-the suffix $-u(h)$ is current. ${ }^{23}$ In other words, if we do not know the 'original' form in dialects of related tribal collectives (like the Mzēnah in Saudi Arabia), a conclusion of sedentary influences being responsible for a change $-a h>-u h$ would be premature; ${ }^{24}$ dialects of groups VII and VIII could have come from the Egyptian mainland with the pron. suffix $-u(h)$ already in place, but they may also have settled in Sinai while (still) using $-a h$ or $-i h$, while only at a later stage copying the -uh suffix from the Mzēnah. On the other hand, a development mirroring this hypothetical development could have also taken place, i.e. the Mzēnah may have arrived in Sinai as $-a h \sim-i h$ speakers, and only later copied the $-u(h)$ from the other southern tribes.

Another example of a more typically 'sedentary' characteristic would be the absence of initial consonant clusters, ${ }^{25}$ such as in examples in ṬwA (except part of ǦbA) išti' "winter; rain", ágrab "watersacks" (which in group I are more typically štiy and grab, see paragraphs 2.3 .5 . in the descriptive chapters). Although such stressed 'original' anaptyctics may

\footnotetext{
${ }^{23}$ It is not possible to decide here which form is more 'Bedouin' than the other. See, for instance, Prochazka 1988:126, where -u(h), -ah and -ih (and also other forms) are listed as occurring in the various dialects of Saudi Arabia.

${ }^{24}$ A suggestion once made to me that the speech of Egyptians among the Ğbāliyyah who were sent in the sixth century by emperor Justinian I to serve and protect St. Catherine's Monastery together with the Wallachians would have had a 'sedentary' influence on the speech of tribes in Sinai at that time must be dismissed as an anachronism; having been sent to Sinai before islam, it is highly unlikely that these Delta Egyptians came there as speakers of Arabic, let alone the Wallachians.

${ }^{25}$ See De Jong 2000:41 (criterion 20: presence of initial CCV in limited morphological patterns). To decide whether initial clusters are tolerated in patterns like CCūC or CCāC, one can add the definite article to such patterns in which the first $\mathrm{C}$ is a 'sunletter'. If

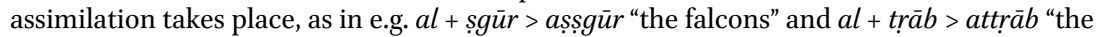
dust", one may conclude that initial CC in such morphophonemic patterns is tolerated.

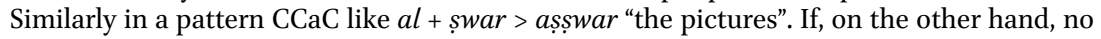
assimilation takes place, but an anaptyctic vowel separates the article and the first C, like in e.g. (i) lisgū $r$, (i) litrāa b and (i) lișwar, we have to conclude morphophonemic base patterns $|\mathrm{iCC} \overline{\mathrm{C}}|,|\mathrm{iCC} \overline{\mathrm{C}}|$ and $|\mathrm{iCCaC}|$. In the latter pattern the preceding (originally anaptyctic) $i$ is then usually stressed on the vowel of the newly available heavy sequence, as in ișwar, or with harmonized vowel áșwar "pictures".
} 
have been the result of dialect contact with sedentary dialects, in the case of Tuwara dialects it is very well possible that the development of incorporating anaptyctic vowels into the morphophonemic base (whereby they became stressable) is one that took place independently, if not altogether imported from other dialects from the Arabian Peninsula with which the tribes arrived in Sinai. In any case, in view of the lack of availability of historical data, we cannot definitively draw the conclusion that this feature is due to dialect contact with 'sedentary' dialects. ${ }^{26}$

One clear indication that the influence of sedentary dialects has been weaker at least than in the north, is the fact that dialects in central and southern Sinai without exception (still) have the full set of interdentals $(\underline{t}, \underline{d}$ and $\underline{d})$ in their phoneme inventories. We have seen that in the north the dialect of the Biyyādiyyah has lost 'neutral' interdentals $\underline{t}, \underline{d}$, and that the dialect of the Axārsah (both of group III) is in a process of losing $\underline{t}$ and $\underline{d}$, both dialects replacing these interdentals with stops $t$ and $d \cdot{ }^{27}$ Such a development has not taken place in central and southern Sinai, and this fact is one of the most telling ones illustrating that dialect contact of sedentary dialects with Bedouin dialects of groups VI, VII and VIII must have been less intense than the dialect contact between sedentary dialects and the dialects of group III in the north, of which many sedentary features are attributable to contact with Delta dialects such as that spoken in the eastern Šarqiyya.

On the other hand, since G.W. Murray 1935 reports that the 'Lēgāt and Șawālhah lived in the Šarqiyyah before they moved to Sinai almost seven centuries ago (see quote in Introduction, I. d., remark ${ }^{{ }^{*}}$ ), there is a chance that these tribes introduced sedentary features into the area, which were later through dialect contact copied into the dialects of other tribes already present in the area, or who arrived at a later time. Conversely, in this scenario, and with reference to a certain number of Bedouin features now present in the dialects of the Șawālḥah and 'Lēgāt, one could perhaps speak of re-bedouinization of these dialects; Bedouin features would then have been (re-)introduced into ȘWA and 'LA as a result of contact with speakers of Bedouin dialects. This hypothesis can however only be

\footnotetext{
${ }^{26}$ One could perhaps imagine 'sedentary' influence from speakers (of various dialects) of (mainland) Egyptian dialects in the town of at-Ṭūr, but then still we would need more data on the intensity of contact between these townspeople and Bedouin tribes in the area, and also on the dialect-type(s) spoken in aț-Țür if we want to arrive at some form of an acceptable conclusion.

${ }^{27}$ See also remarks in De Jong 200o:621-625.
} 
corroborated if we could somehow definitively establish the shape of an earlier type of eastern Šarqāwiy, which is not possible at this stage. We simply do not know the characteristics of the dialect-type (or even different types) - the degree of 'Bedouinness' or 'sedentariness' — spoken in this eastern Delta region in the fourteenth century.

What makes this scenario of 're-bedouinization' less likely, is that one would expect hypercorrections in the re-bedouinized dialects. An example of such hypercorrection would be, in case of a 're-split', an interdental reflex for originally plosives, like $\underline{t}$ for ${ }^{*} t$, or $\underline{d}$ for *d. I have seen no evidence of such or comparable hypercorrections.

It is more likely that these collectives (the 'Lēgāt and the Șawālhah) kept speaking their own dialects during their stay in the eastern Delta, or at least their dialects were not extensively influenced by a sedentary type comparable to types heard in the Delta today, and that such 'rebedouinization' did not take place when they moved to Sinai. This situation would be comparable to the situation of the dialect spoken by the Rašãydah, who are known to have continued to speak their own Nağdiy dialect (in the privacy of their own homes, in any case) in Sudan and also in other areas, even though they have been away from their former abode in the Arabian Peninsula for almost two centuries (since the second half of the 19th century).

\section{f. The Locations of Isogloss Bundles in Central and Southern Sinai}

Isogloss bundles coincide with boundaries of tribal dirahs, simply because we have chosen geographical borders between the tribal areas (sg. dirah) of different tribes as the location to draw these isoglosses onto the map. To a degree, this is of course artificial, but experience has taught that often the speech of members of the same tribe in the same tribal area will not show very many differences..$^{28} \mathrm{I}$ did however notice some differences between members of the Ğbāliyyah who live near the monastery of St Catherine, and those who live some 40 kilometres away in Wādiy Fērān/ Wādiy aš-Šēx, in and near Mrēr and aț-Ṭarfa. ${ }^{29}$ Similarly, Mzēnah who live near the coast will use $\check{s} u \dot{g} !$ as the genitive exponent, whereas hagg appears to

\footnotetext{
${ }^{28}$ See also remarks in De Jong 2000:19.

${ }^{29}$ Hobbs 1995:140 reports that of the estimated 300 families (or 1,500 souls) of the Ğbāliyyah, around half live within a 5 kilometre radius fom the monastery, and the other half live in aț-Ṭarfa.
} 
be more current with Mzēniy speakers who live more inland, i.e. in the mountains (see 3.1.11.)..$^{0}$

Much clearer than in northern Sinai, some of the major isogloss bundles found in central/southern Sinai coincide with visible geological features of the landscape. From the fact that isoglosses in this study are drawn into maps to coincide with borders of tribal dīrahs, and borders of some of these dirahs coincide with features of the landcape,$^{31}$ the coincidence of isogloss bundles with natural features of the landscape will come as no surprise. In cases where such a natural feature of the landscape is an obstacle for the traveller, isoglosses may accumulate to form thicker bundles. This is no news, of course, since examples from Europe or elsewhere, like rivers (i.e. where they hinder traffic), swamps, mountain ranges, etc. are plentiful..$^{2}$

In Sinai, one of the clearest examples of such coincidence of isogloss bundles with a natural feature of the landscape is the southern escarpment of the Tìh plateau, ${ }^{33}$ which is also roughly the location of the major isogloss bundles (numbers -16-, -20- and -24- in MAP 88, see appendix) running more or less southeast-northwest through Sinai between dialects of group I (to the northeast) and dialects of group VII (ȘA) and group VIII ('LA) (to the southwest). Although the dialect of the Badārah (assigned here to group I) is now spoken to the south of this escarpment as well, this tribe is originally from the Tìh plateau, where some of their families may still be found..$^{34}$ In figure 1 of the appendix the escarpment

$3^{30}$ Palva 1984-1986:307 remarks that hagg "is the genitive marker used by many dialects of the Arabian Peninsula".

${ }^{31}$ A practical way for tribes to decide on the border of their territories is to agree on features of the landscape to represent this border. An example is the "Fjord" on the coast of the Gulf of 'Aqabah (location appr. 29.25.50 North and 34.49.50 East, see Google Earth), which is accepted by Tarābīn and Ahaywāt to be the eastern end of the border between their dīrahs.

${ }^{32}$ In northern Sinai we identified an 'invisible obstacle' coinciding with such a major isogloss bundle: due to the lowly social status of the Dawāgrah major isogloss bundles coincide with the borders between their dīrah and the dirahs of neighbouring tribes, see De Jong 2000:653 (MAP oo in appendix), isogloss bundles numbers 6 and 8.

33 The Tîh plateau is Eocene limestone, the high mountains to the south are part of a Precambrian Crystaline base, see webpage http://www.awayaway-sinai.net/main/about_ sinai.htm (accessed 10-18-2010).

${ }^{34}$ Oral communication from members of the Badārah in the field, and who now live in ar-Ramlah, the sandy area just to the south of this escarpment. Von Oppenheim 1943:152153 also mentions the Bedāra (in his transcription) as one of the oldest tribes in Sinai, living on Ğabal 'Iğmah, who were in a hilf (alliance) with the Tayāha in older times, after which they had 'Beziehungen' (relations) with the Țuwara ('Lēgāt) as well, and have 'now' (i.e. in his day) returned again to their old protectors the Tayāha. I had the impression during my visits that they had now returned to their earlier protectors the 'Lēgāt again. 
is visible in the map as the darker shade of grey between the brownish/ pink area to the south (the area aptly named ar-Ramlah, indicated on the map as Debbet er Ramleh) and the high granite mountains of aț-Tūr and the grey area to the north (limestone plateau of at-Tìh). This escarpment is very difficult to traverse. ${ }^{35}$

Another example is the isogloss bundle between the dialect of Tarāain of Nwēbi ' and that of the Mzēnah ( $\mathrm{nr}-28$ - in MAP 88): although both tribes live on the sandy plain of Nwēbi in the Gulf of 'Aqabah of the mouth of Wādiy Watīr - the Tarābīn in the northern area and the Mzēnah in its southern area-farther inland the border is the mountain range of Ğabal Gunnah running more or less east-west, ${ }^{36}$ as I was told by my Tuṛbāniy informant.

In Wādiy aš-Šēx the tribal border between the Mzēnah and Ğbāliyyah is the (nowadays) asfalt road that leads through Wādiy aš-Šēx (to Wādiy Fērān): at the stretch of this road to the west of at-Ṭarfa Mzēniy territory lies to the north and the territory to the south is claimed by the Ǧbāliyyyah.

The dialects of Baniy Wāșil and the Mzēnah show a number of important similarities. Since the Baniy Wāṣil are said to originally have been speakers of a group I-type of dialect ${ }^{37}$ - and if this is true - the dialect that they speak today must be the result of extensive influence from Mzēniy. On the map the territories of Baniy Wāșil and Mzēnah are separated by the territory of the Awlād Sa īd, which might prompt the question why their dialect (ASA) is not more like that of group VI (i.e. BWA and MzA), especially if dialect contact is assumed to be the cause of the development of older BWA towards the dialect type of MzA: how could this contact take place across an area inhabited by another tribe, and how can it be that the dialect of this separating tribe was not or at least much less influenced by MzA?

The answer is that the map in this case does not give a realistic picture of where members of the tribes actually live: the Awlād Sa īd live much farther inland (the mountainous area in and around Wādiy Șlāf; for the location see fn 2, p. 115 in Introduction to Chapter II), thus leaving the

\footnotetext{
35 For a map showing the passes leading down from the Tîh Plateau to the 'Dividing Valleys' (of which the ar-Ramlah area is a part), see Greenwood 1997:35 (Figure 3-6. The Dividing Valleys).

${ }^{36}$ This mountain is erroneously named Jabal Jannah on Google Earth, coordinates are appr. 28.52.30 North, 34.07.50 East.

${ }_{37}$ Oral information of sources in the field. See also a comparison of MzA and BWA below.
} 
sandy coastal plain near the town of at-Tūr, which they claim as their dīrah, deserted. The Baniy Wāṣil and Mzēnah can travel through this area freely, ${ }^{38}$ but simply will not settle in this empty land, which is also considered to be Sa îdiy territory.

Territorial disputes also occur from time to time. The latest (in 2008) large scale conflict was between 'Lēgāt and Taṛābīn, when the 'Lēgāt, supported in their territorial ambitions by the Ğarăğrah tried to move into Tựbāniy territory south of Ṛās Șadr. The Tarāāin did not sit idly and watch it occur, but instead rode out to defend their territorial claims in an armed conflict. The matter was settled later in a Bedouin court of justice. Not only were the 'Lēgāt sentenced in this Bedouin court of justice for their expansionist aspirations, the Ğarāğrah too were fined a substantial sum for choosing the 'Legiy side in this dispute. ${ }^{39}$

\section{g. A 'Virtual' Isogloss Bundle, Number-39-: BWA and MzA}

To show the relative typological proximity of the dialects of the Baniy Wāṣil and Mzēnah, a 'virtual' isogloss bundle (number -39-) was drawn into the map (positioned in the Gulf of Suez).

A direct comparison through multi-dimensional scaling already shows their relative proximity. In terms of calculations done for the 'step method' this proximity is expressed as $13.4 \%$ of differences as the outcome of the total of comparisons.

We see that BWA is 'partially' or 'wholly' characterized by a number of features that are more of the group I type than of the MzA type. To list examples:

- Like in most group I dialects, raising of short $a$ in CaCCāC has not led to morphological restructuring (then > CICCāC), but is absent or rare (unlike the situation in surrounding dialects, where it is frequent and either optional or compulsary) (see MAP 22).

- The use of a sg. fem. pronominal suffix -kiy, either when following $\bar{v}$, or invariably so (i.e. preceded by any combination of vowels and/or consonants, like in group I) (see MAP 37).

${ }^{38}$ This is not to say that a tribe would otherwise normally deny a traveller passage through their dīrah. The point is that contact between Mzēnah and Awlād Sa îd and between Baniy Wāṣil and Awlād Sa îd is likely to be less frequent, and contact between the Mzēnah and Baniy Wāșil to be more frequent than the situation reflected by the map may suggest.

39 Oral communication from Turbāniy sources in the field. 
- BWA is the only dialect in the area which predominantly uses demonstrative forms with initial $h \bar{a}-$, like in group I (see MAPS 39 and 40).

- BWA is the only dialect in the area which uses the adverb hniy for "here" (see MAP 46).

- The system of negated personal pronominals is basically like in group I (see MAP 79).

- The interrogative "when" is like in group I matā, not like in the surrounding dialects (where one will hear (i)mtēh, mtēn, or mitēn) (see MAP 82).

- 2nd p. sg. masc. imperfect forms and sg. masc. imperatives of mediae infirmae verbs with shortened long vowels are not current (i.e. the situation is like in group I). In surrounding dialects such shortening of the long vowel occurs regularly (see MAPS 84 and 85).

Of the partial differences, it is striking that a form used parallel to a form also known in MzA is often of the type found in group I as well. Examples are:

- Like in group I, a reflex (with short vowel) -á (when preceded by an emphatic) is used as parallel to (with long vowel) $-\bar{a}\left({ }^{\prime}\right)$ (like in surrounding dialects) for *-a('), e.g. fid á" "free time", but rh $h \bar{a}^{3}$ "hand mill".

- Like in group I, widd is used to express "want, need", parallel to bidd, the latter being current in surrounding dialects of group VII (see MAP 73).

- Like in group I, raising of $a$ in closed syllable preceding stressed $\bar{e}$ (e.g. lammèt > limmèt) is often absent, as opposed to the situation in surrounding dialects where such raising is current (see MAP 75).

- Like in group I, the baking sheet (for the preparation of bread) is called a șāğ (as opposed to šāz in surrounding dialects). The game of siğih ( sìğih in group I), however, is referred to as šlzih, like in surrounding dialects.

- The demonstrative for the pl. com. "these" may be heard with initial $h \bar{a}$ - (i.e. $h \bar{a} \underline{d} i l)$, as opposed to surrounding dialects, where only forms without such initial $h \bar{a}$ - are current (this may be due to MzA, which has hädil as a parallel form as well, or may be due to forms in group I, where forms with initial $h \bar{a}$ - are predominant).

The combination of these features points toward an earlier group I type of dialect for BWA. This should be seen in combination with the fact that the Baniy Wāṣil were among the earliest tribes to arrive in Sinai (between 1oth and 13th centuries, and perhaps even earlier, see Bailey 1985:33-35, and remarks made above in the Introduction, I. d.). Chances that BWA 
acquired these group I features through dialect contact with one of the group I dialects are not great, since the dīrah of Baniy Wāṣil does not border on any of the group I dirah's (nor do I have evidence that it ever did).

The fact that BWA has been grouped together here with MzA to form group VI, is due to the features it shares with MzA. Notwithstanding the relic forms that are assumed to have their origin in its earlier group I-type, some of these features are truly unique for group VI (which makes their origin elsewhere in the region unlikely). E.g.

- The combination of (velarized) kbār and (unvelarized) kt $\underline{\ddot{a} r}$ (like in $\mathrm{MzA}$ ) contrasting with (both velarized) kbār and ktāar in group I, and (both unvelarized) $k b \bar{a} r$ and $k \underline{\underline{a}} \vec{a} r$ in surrounding dialects (see MAP 4).

- Raising of $a$ in open syllable preceding stressed $a$ and also $\bar{a}$ is like in MzA.

- Initial (')a- in "mother": 'amm (like in MzA and group I) as opposed to 'umm in surrounding dialects (see MAP 26).

- The form of the preposition "with" + 3rd p. sg. masc. suffix is m 'uh "with him" and is identical to the form in MzA (and 'LA and HmA), but surrounding and group I dialects have different forms (see MAP 48).

- The 3 rd p. sg. fem. perfect of $i$-type is CiCCat like in MzA, but surrounding and group I dialects have other forms (see MAP $5^{2}$ ).

- The combination of 3 rd p. sg. masc. and ist p. sg. com. imperfect forms of "come" are yiğ́y and iǧíy is like in MzA, but forms differ from surrounding and group I dialects (see MAP 61).

- For the pl. masc. personal pronominal for "they" huwwa is current, like in MzA (but most group I dialects have hum(ma)) (see MAP 78).

- The reflex for final ${ }^{*}-\bar{a}$ in $a$-type tertiae infirmae $(y \bar{a})$ verbs is usually (stressed) -í, like in mišsi. ligí, nisí (see MAP 86).

The grouping of MzA and BWA together in the same group is also supported by the outcome of the plots generated by the SPSS programmes Proxscal and Alscal: the MDS plots (see pp. 373-374), the dendrogram (see p. 375), the multi-dimensional colour plot, and-although to a somewhat lesser extent - the percentages calculated using the step method (see Conclusions, III. b.). 


\section{Methods of Illustrating Dialect Differences}

\section{a. Some Remarks on Methods of Illustrating Typological Similarities/ Differences of Dialects}

One method of illustrating typological distances between dialects is to take the selection of features as they have been recorded in the data set. In this data set every dialect receives its own horizontal row and selected features are recorded in vertical columns. Presence of a feature is marked with the number " 1 ", absence of the feature with the number "o". When parallel forms have been recorded in one dialect, presence of these parallel forms will be marked " 1 " in an equal number of columns.

On the basis of this data set, a distance matrix is then calculated; for each pair of dialects a relative typological distance is calculated (see the distance matrix in the appendix p. 376) (for dialectometrical measurements of distances based on differences and similarities, see Chapter 11. 2. In Behnstedt and Woidich 2005).

Using the calculated distances from the distance matrix, dialects are then plotted into an imaginary three-dimensional cube.

To each of the three dimensions represented by axes $\mathrm{X}, \mathrm{Y}$ and $\mathrm{Z}$ one of the three basic colours red, green or blue is assigned.

Each axis is subdivided in values between zero and 255, in which zero represents o value for the basic colour, and 255 represents maximum value for that same basic colour on this axis. ${ }^{40}$

In this way every point inside the cube receives its own set of three coordinates, the combination of which is unique. Since these coordinates are represented by intensities of basic colours, different colours are produced according to the mix of the different values for these basic colours.

We then take these colours back to the geographical map, and paste them into the dirahs of the tribes whose dialects are represented by these colours. The result is a map in which typologically more similar dialects will show relatively similar colours, whereas more strongly differing dialects will receive more strongly differing colours on this map. An example of the situation in Sinai can be found on figure 8a in the Appendix.

$4^{40}$ For an introduction to this method of multi-dimensional scaling, see the webpage (in Dutch) by Peter Kleiweg http://www.let.rug.nl/ kleiweg/Lo4/Tutorial/ti.html.nl (accessed 10-18-2010), which is part of the Linguistic Atlas of the Middle and South Atlantic States (LAMSAS) project at the University of Groningen (Netherlands). 
This map clearly shows the dialect groups as clusters in similar shades of colours:

group I is mainly different shades of light green (and greyish for TAS and TAN), group II is purplish red, group III is red/dark orange (with a similar shade for eŠA) group IV is light blue, group $\mathrm{V}$ is purple, group VI is sea green. group VII is purple/violet. group VIII is brownish / dark olive green.

When the three basic colours are assigned to different axes, naturally the colours will change. Examples are figures $8 \mathrm{~b}$ and $8 \mathrm{c}$ in the Appendix.

These maps also appear to corroborate claims of genealogical relatedness of some tribes. The dialects of TAS and TAN are spoken by two different branches of Tarābīn, who live approximately 200 kilometres apart. The fact that they are typologically near is clearly illustrated in the 2-dimensional MDS plots generated by Proxscal and Alscal (see pp. 373-374), where they have been plotted near each other. It is also illustrated by the 3 -dimensional colour MDS plot, where the two dialects receive very similar colour shades. The dialect of the northern branch of Tarāain (nTA) is however typologically further removed, which is also illustrated in the different plots.

In the same way, the proximity of the two dialects DbA and HwA seems to corroborate claims that the two tribes are genetically related, or in any case may have been part of the same confederation in earlier times; the Dbūr are said to have split off from the Hwētāt as a 'āylah. ${ }^{41}$

Compare these maps to map 88 of the appendix in which the differences have been interpreted and where every group is represented by one assigned colour.

Group I : yellow

Group IV : light blue

Group VII : light brown
Group II : orange

Group V : grey/blue

Group VIII : dark yellow
Group III : pink/light red Group VI : green

${ }^{41}$ Von Oppenheim 1943:154-155 already lists this collective (Debūr in his transcription) as a sub-tribe of the Hwēțāt, adding that they are "apparently a branch of the Debūr of Transjordan" (see ibid.:155, note 5). At-Tayyib 1997:107 also lists the Dubür as one of the branches of the Ḥwēțāt. 


\section{The dīrahs of the Hiwètāt and Ahaywāt}

Although interviews with Ḥwētāt were recorded in the area of Ğidy, I have not met with Hwētāt from the area more to the north in the triangular area drawn on the map between 'AyA and nTA territory. For the area of Ahaywāt to the south of this HwA area, I have spoken to some Ahaywiys who live near the road from Rạa Șadr to the main (west-east through central Sinai) road Mitla ${ }^{42}-$ Nixl, where some families of the Ahaywāt live, not far north of Qal'at alĞindiy. ${ }^{43}$

\section{b. Multi-Dimensional Scaling in a Two-Dimensional Map}

The MDS plots in the Appendix (pp. 373-374) show a number of interesting results. First of all, the plot supports the grouping of dialects and observations made earlier in De Jong 2000:44

- Balawiy Arabic (BaA) is shown to be nearest to (other) group I dialects, but its relative distance from these can still be interpreted as illustrative of the special place it occupies within this group. ${ }^{45}$

- To illustrate the relative typological proximity of group III dialects in the north to the dialect of the eastern Šarqiyyah (eŠA) in the Nile Delta, a 'virtual' isogloss bundle was introduced in De Jong 2000. ${ }^{46}$ The MDS plot also clearly shows this typological proximity.

- The MDS plot corroborates the separate typological status (as not being part of the northern Sinai dialect continuum) of Dwègriy (DA, group IV) and 'Arāyšiy ('AA, group V). The plot also shows that they are sufficiently far removed from other dialects to be considered as separate 'groups'.

- The MDS plot shows that groups I, II, III and eŠA (eastern Šarqāwiy) of the north are in a linear sequence ('west-east' from left to right in the MDS plot), which reflects the typological continuum they form (geographically running in the opposite direction of the MDS plot).

\footnotetext{
${ }^{42}$ Originally Uṃm It

${ }_{43}$ Qal'at al-Ǧindiy is located at appr. 29.51.04 North and 33.07.50 East, see Google Earth.

${ }_{44}$ Observations made here are really based on the comparison based on 95 features which were selected to serve as criteria. Other characteristics not represented in this comparison further illustrate the same results.

45 See remarks in De Jong 2000: $57-58$.

${ }_{46}$ There bundle number $-21-$, cf. remarks $611,615,619,622,625$.
} 


\section{c. Other Results of the MDS Plots}

- In De Jong $\mathbf{2 0 0 0}^{47}$ a remark from an older speaker of Smēniy (SaA of group II in the north) was quoted, in which he claimed that his tribe had until a hundred years earlier lived in at-Türr, ${ }^{48}$ where they had owned datepalms. The MDS plot Proxscal Squared Euclidean clearly illustrates the dialect of the Hamādah (HmA of group VII) as being relatively nearest to that of the Samānnah. The MDS plot generated by Alscal (Euclidean Binary, see pp. 373-374) however does not produce the same result. I have no explanation for this difference between these two plots.

- The dialects of Baniy Wāșil and Mzēnah are plotted relatively near to each other. This is supported by the relatively limited number of isoglosses in the 'virtual' isogloss bundle introduced in the preceding pages, which also illustrates such relative typological proximity.

- The dialect of Baniy Wāșil (BWA), which was said by informants to have originally been of the group I-type, is plotted nearer to the group I dialects than any of the other non-group I dialects.

A problem with the outcome of the two-dimensional MDS plot Squared Euclidean Binary (see p. 373) generated by Proxscal is that the distance between e.g. BWA and ĞrA (of different groups: VI and I resp.) is plotted as shorter than the distance between, e.g., ĞrA and MlA, which are of the same group (both of group I), whereas dialects that are typologically more similar should be plotted nearer to each other than dialects that are less similar. The reason is that the number of dialects in group I to be incorporated in the plot is so great that it causes excessive stress, which results from 'cramming' hundreds of dimensions into a two-dimensional space. The result is that a less realistic representation like the one discussed here becomes unavoidable. To illustrate that it is stress that causes such distortion, all group I dialects causing such stress have been omitted from the MDS plot below, except ĞrA and MlA.

In this Proxscal MDS plot we see that the distance between ĞrA and MlA has been restored as being relatively shorter than the distance between ĞrA and BWA (dissimilarities are: BWA - MlA = 76, ĞrA - MlA

47 See p. 246. For illustration of similarities of these dialects cf. MAPS in the appendix of this volume.

${ }^{8}$ The name at-Ṭūr is generally used to refer to the high mountainous area in southern Sinai, roughly where the Tuwara tribes live. 


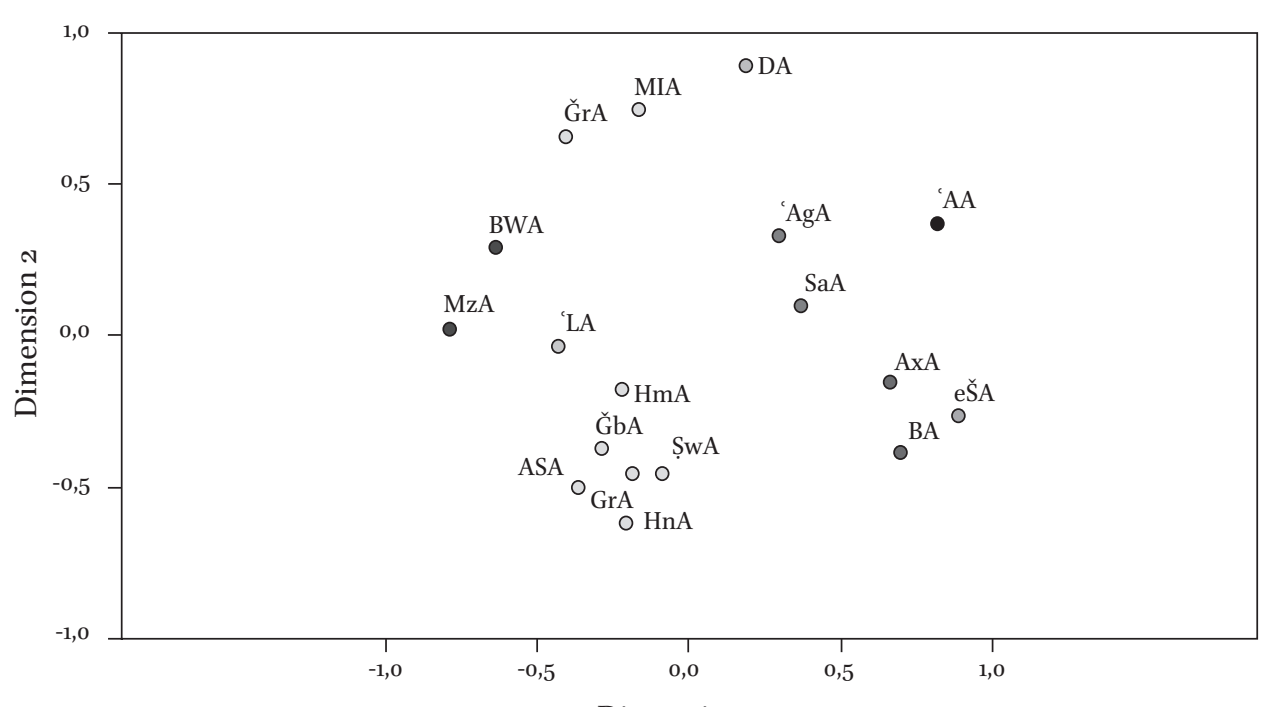

Dimension 1

$=44 ;$ ĞrA - BWA $=66 ;$ MlA - BWA $=76 ; 49$ binary Euclidean distances in the proximity matrix are: $\mathrm{BWA}-\mathrm{MlA}=8.718$; ĞrA $-\mathrm{MlA}=6.633$; ĞrA $\mathrm{BWA}=8.124$, see the proximity matrix on p. 376 ).

Excessive stress causing such distortions in these two-dimensional representations is less problematic ${ }^{50}$ in the MDS plot Euclidean Binary generated by Alscal of the SPSS (see p. 374).

Another interesting aspect of the different methods of multi-dimensional scaling is that these invariably lead the same grouping of dialects. Although different methods applied may inside the generated MDS plots lead to different positions of dialects (like 'AA and DA) that have relatively little in common with the other dialects spoken in Sinai, the different MDS plots do produce comparable clusters of typologically related groups of dialects (see also two other MDS plots and the dendrogram on p. 375).

In addition, we notice that the dialects of groups VI, VII and VIII are all plotted in the southeastern quadrant ${ }^{51}$ of the plot generated by Alscal (Euclidean Binary). The importance lies in the fact that, given the diverse

\footnotetext{
49 These numbers are only to be interpreted as distances relative to each other; the greater the number, the greater the distance.

$5^{\circ}$ By "less problematic" I mean that the resulting plot better represents my own subjective impressions of the typological distances of the groups involved.

${ }^{5^{1}}$ The fact that these three groups are plotted in this quadrant is coincidental to some degree, but the relative proximityof the three groups is not.
} 
origins of the tribal communties before they came to Sinai (and at different times in history), dialect contact is highly likely to have been the acting force in bringing these dialects typologically nearer to each other in a process of levelling. ${ }^{2}$ In this way the dialects of the different tribes have coalesced (though not entirely) to form a 'phylum', ${ }^{53}$ which now covers the southern tip of Sinai. Several processes of focusing must have taken place. One clear example is the spread of the ${ }^{-(u)} k$ (masc.) and ${ }^{-(i)} k$ (fem.) pronominal suffixes for the 2nd p. sg.; although the proposed development described above (cf. Chapter I, 3.1.12.2., NOTE) may be plausible, it is highly unlikely that the different different tribes who arrived in southern Sinai at different times in history all had these suffixes after having all gone through the same process of innovation (i.e. the reinterpretation of morpheme boundaries) independently and before their arrival in Sinai. A much more plausible scenario is that these suffixes originated in one of the dialects involved in dialect contact, after which they spread throughout the southern region. This development may be difficult to date, but we know that it must have taken place more than a century ago at least, because until ten years ago these suffixes were still present in the dialect of the Samānnah in the north, who had emigrated from southern Sinai towards the end of the nineteenth / beginning of the twentieth century (see De Jong 2000:246).

\section{d. Grouping Dialects Using a Dendrogram}

To arrive at a relatively logical grouping another tool used is a dendrogram ${ }^{54}$ (generated with the Hierarchical Cluster Analysis of the SPSS) to cluster the dialects of Sinai (including Negev Arabic, DA). It is important to remember that a dendrogram illustrates degrees of similarity (or dissimilarity), and

\footnotetext{
${ }^{52}$ See remarks in Trudgill 1986:39, where the relevance of the geographic parameter of diffusion models is stressed.

See also Palva 2008b:401 "[...] the Tawara tribes have lived in close alliance since the 17th century (Oppenheim 1943:156-157), and the earlier dialectal differences must have faded away long ago".

An alternative interpretation could be that these dialects were already much alike before the tribes came to Sinai, but given the heterogeneneous history reported for the different tribes in various sources, this is far less likely; in any case this alternative interpretation would fail to explain the current typological position of ĞbA, whose speakers must have come to Sinai in the fifth century CE as non-native speakers of Arabic (see also remarks in fn 24, p. 321).

${ }_{53}$ Other than a possible genetic relationship in the distant past, this term is not meant to suggest a relatively recent common ancestor.

${ }^{54}$ See also Behnstedt and Woidich 2005:129.
} 
that we should not conclude a genealogical relationship. A dendrogram generated for all dialects in Sinai is (grouping with Roman numbering was done by hand, see figure 6 in the appendix for the colour version):

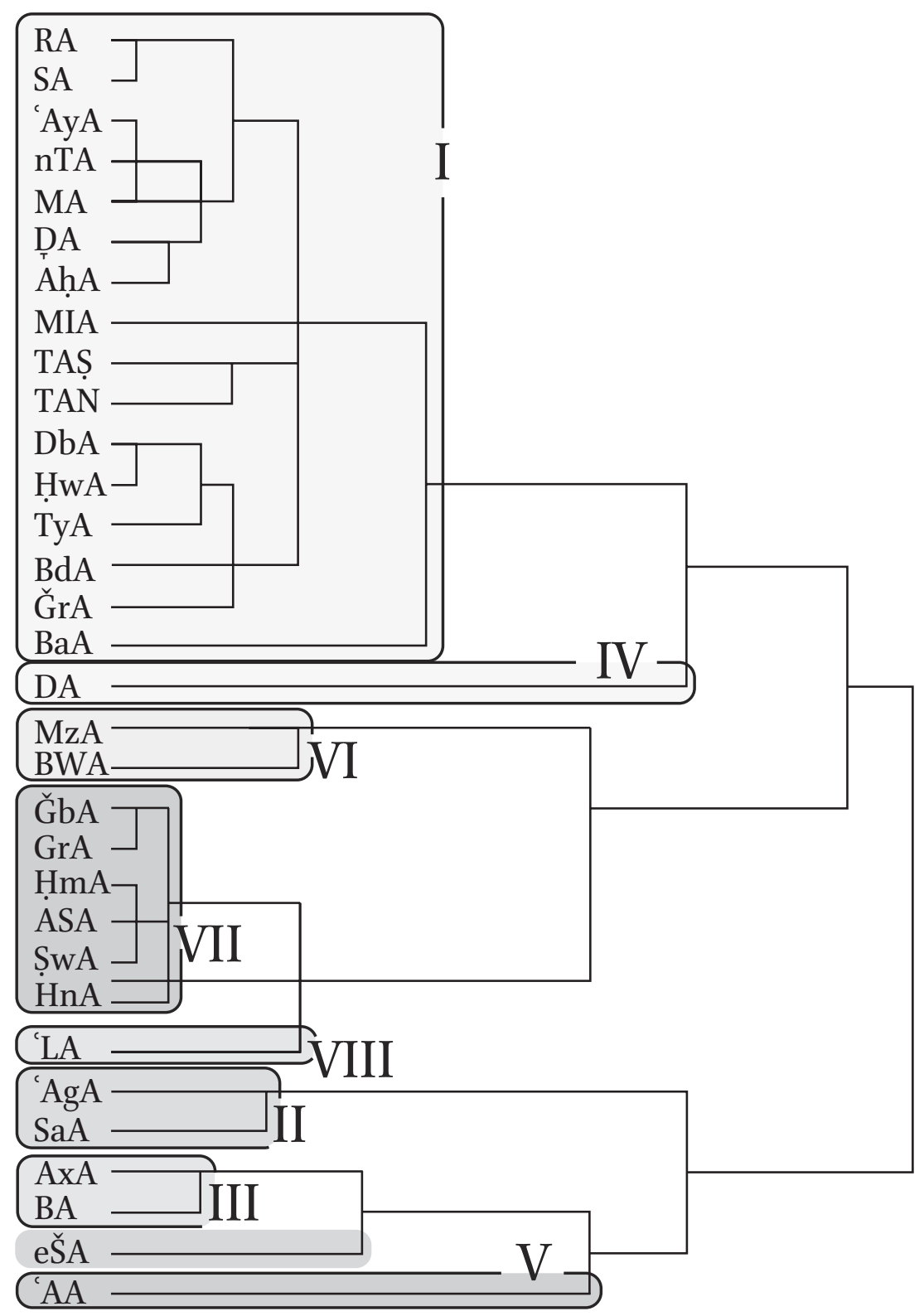

Dendrogram of dialects of Sinai 
We see here that the Group I dialects quite neatly cluster together, with BaA occupying a special place inside this group. BaA 'branches' at a lower level, farther to the right, than the other dialects (see remarks in De Jong 2000:57-58). Groups IV and V branch at a relatively low level as well (even farther to the right than $\mathrm{BaA}$ ), which supports the interpretation of these dialects as separate groups.

Clustering of the dialects that form groups II and III is also clear from this dendrogram. For remarks on decisions to group clusters of dialects in groups VI, VII and VIII in this manner, see remarks in Conclusions, III. c.

The dendrogram also shows that the dialect of the eastern Šarqiyya (eŠA) and the dialects of groups III (BA and AxA) and also V ('AA) are all on the same longer branch. This is due to the fact that these dialects are all more of the sedentary type (in comparison to the other dialects represented here in groups, which are more of the Bedouin type).

A plausible interpretation of the existing situation from a sociolinguistic perspective is that the different groups, in as far as dialects were not genealogically related, have developed from a diffuse situation (or situations, since the different tribes arrived at different times in history) towards a more homogeneous situation through dialect contact, in which certain original forms must have been lost due to processes of koineization through stages of levelling (simplification, reduction in irregularities, focusing, dropping minority and otherwise marked speech forms that exist parallel) and which resulted in a synchronically relatively stable dialect (see Trudgill 1986:107-108 and remarks in De Jong 2000:28-29).55

To conclude such a development becomes particularly plausible if we consider the case of the 2nd p. sg. masc. and fem. pronominal suffixes ${ }^{-}{ }^{u} k$ and ${ }^{-} k$ (resp.); a scenario in which different tribes of different origins arrived at different times in history, but were all already using these pron. suffixes is highly unlikely (see remarks in the preceding paragraph). We may not know where these suffixes originated, but we do know that they spread among this group with its heterogeneous background that currently exists in southern Sinai. Perhaps these suffixes were imported into the area by one of the tribes who arrived there, or perhaps these suffixes even came into being locally as 'interdialect forms' (see Trudgill 1986:62).

\footnotetext{
${ }_{55}$ For processes of 'Konvergenz' leading to 'Nivellierung', bringing various dialects closer together, see Diem 1978.
} 


\section{e. What Informants Say}

In the course of this research several claims were heard made by informants concerning the relationships between the different tribes of Sinai. Although I have chosen not to use these comments for the typological classification and grouping, I consider them interesting enough to be mentioned here. Below is a list of these claims and in comments I have indicated how the results of the MDS plots and the dendrogram (in the appendix) might relate to these claims ${ }^{56}$ (the question of whether or not these statements are true is not investigated here). ${ }^{57}$

Remark: the Dbūr are said to be related to (i.e. they originally split off as a family from) the Hwētāt.

Comment: when we look at the MDS plots, we see that their dialects (DbA and HwA resp.) are indeed plotted closely together inside group I. The dendrogram shows the same.

Remark: the Ğarāğrah are said to be related to the Masāīì (in the northwest), who are in turn said to be related to the Ahaywāt (living around Nixl and Țāba).$^{8}$

Comment: the dialects of the Ahaywāt and Masāīd (AḥA and MA resp.) are indeed plotted closely together inside group I. The dialect of the Ğarāğrah (ĞrA), however, is not plotted very near to AhA and MA (resp.). The dendrogram shows the same.

Remark: the 'Lēgāt are said to be descendents of the neigbouring Ṣawālhah.

Comment: the MDS plots position their dialects relatively near each other. In the dendrogram these two dialects do not appear very near each other.

\footnotetext{
${ }^{56}$ There is of course also the chance that informants conclude a relationship based on features perceived to be similar in the dialects spoken by these tribes.

${ }^{57}$ One could even imagine that people 'invent' a genealogical relationship based on their perception of linguistic similarities with the dialect of another tribe, or simply because they for some reason like to be associated with another tribe or certain other tribes.

Much of the claims listed here can be checked against the information given in Introduction I. d. and in the relevant sources mentioned there.

${ }_{5}^{8}$ See also De Jong 2000:11.
} 
Remark: The Garāršah are said to be a section of the Șawālḥah (see also Bailey 1985:33).

Comment: the MDS plots and the dendrogram indeed cluster these two dialects relatively near each other.

Remark: the Tarābīn are said to be related to Biliy (in the north), but this is quite remote in the past. ${ }^{59}$

Comment: a relationship between (any branch of) the Tarābīn and Biliy - other than that they have been grouped together ${ }^{60}$ - is not evident from the MDS plots or the dendrogram.

Remark: the dialect of the Baniy Wāṣil was more like the dialect-type spoken by group I tribes, but it has changed under influence of dialects of 'other' (not further specified) tribes.

Comment: the MDS plots indeed show that Wāṣliy (BWA), as one of the dialects of the southern groups VI, VII and VIII, is typologically nearest to the group I-type dialects. The dendrogram does not show a direct connection.

In general, one could conclude that remarks made by informants are often on the mark, or quite near it. G.W. Murray's (1935:256-257) remark on Bedouin in southern Sinai that "among themselves, they can distinguish each tribe and subtribe by their looks and dialects..." is true for the entire region.

\section{A Comparison of the Dialect of the HWwēṭāt of Southern JoRDAN AND THE HWwêț̄itT OF SINAI}

Prompted by some additional remarks made by Professor Heikki Palva on the dialect of the Hwēțāt, which were partly in reaction to my own remarks on his description of their dialect as spoken by this tribe in southern Jordan, I feel encouraged to once again add a few of my observations.

59 Stewart (1991:106) reports that the Tarābīn were part of the Baniy 'Ațiyya.

6o See also De Jong 2000:57-58, fn 3 on the special position of BaA inside group I. 
In this research it is assumed that members of the same tribe who live in the same dirah and are in regular contact with each other will also speak the same dialect. ${ }^{61}$

When members of the same tribe have been living in different locations, and have been relatively isolated from each other for longer periods of time, their dialects are bound to show differences, and one may expect that the longer the isolation has lasted, the more differences will have developed. ${ }^{62}$

The majority of those who identify themselves as Hwētāt are actually found in southern Jordan and in the adjacent far nortwestern corner (the northern Hiğāz) of Saudi Arabia. In older times many of the Hwēțāt settled on the Egyptian mainland, a large group of whom were found around Bilbēs in the eastern Nile Delta. The Hwẹtāt in Sinai are not very numerous, and a small settlement inhabited by them is Ğidy ${ }^{63}$ in the north of Sinai. The Hwêtạt of southern Jordan are said to be an amalgam of different groups of (semi-)sedentary population, many of whom are originally not of Bedouin stock. ${ }^{64}$

My earlier remarks concerned the typological status of the dialect of Hwêtạât in Jordan, ${ }^{65}$ and whether perhaps their dialect formed part of a transition to a more Nağdiy type of dialect. The following is a comparison of Hwētiy spoken in Jordan (referred to here as HwJ) as described in Palva 1984-1986 (in this comparison the structure of this article is largely followed).

${ }^{61}$ This is a sociolinguistically inspired approach that has proven to be a very workable principle in the case of (sometimes still (semi-) nomadic) Bedouin tribes. There are exceptions, of course. See also remarks in De Jong 2000:19.

${ }_{62}$ Either as a result from autonomous developments inside the dialect itself, or as a result of change induced by contacts with speakers of other dialects.

${ }_{6}$ Since the area was said to be teeming with military (for the very strategic Ğidy pass about $20 \mathrm{~km}$ north of the Mitla pass), I had interviews there conducted for me by others. The approximate position of the village would be 30.12 North, 33.04 East, just to the northwest of Ğabal alĞidy, and to the north of Șadr alḤaytān, see Google Earth (where it is indicated as Gebel Heitan).

${ }^{64}$ Oral communication from a Hwēțiy šēx from al-Ǧafr interviewed in 2008 in al-Husayniyyah in southern Jordan. He told me that several families or clans had joined the tribe as duxala (Classical Arabic duxalä'), i.e. "people seeking refuge and protection".

See also remarks in Palva 2008b:402 "[the Hwēțāt] probably are descendants of an old local population (ahl ad-dìre) (Musil 1926:20), whose culture for centuries has fluctuated between seminomadism and semisedentarism".

${ }_{6}$ See De Jong 2000:627-630. 
I have added notes referring to Hwēțiy poetry as recorded in Holes and Abu Athera 2009 when forms appearing there are different from Palva's description or from my own findings. These poems will be referred to as 'Barrāk'. ${ }^{66}$ The abbreviation HwA is used her to refer to may own findings for the dialect of Hwêțāt in Sinai. For the sake of brevity, the emphasis in this comparison is on highlighting differences between HwA and HwJ, while briefly mentioning some similarities.

The texts of the poet Barrāk in Holes and Abu Athera 2009 are essentially the interpretation of the authors ${ }^{67}$ of written texts, and are not based on audio recordings. Apart from that, it is known that for poetry not every day spoken dialect is used, but a (higher) register considered to be more appropriate for this purpose. I shall therefore merely mention details of interest without drawing any conclusions from the Barrāk material.

\section{Phonetics}

The inventory of phonemes is almost identical (see Palva 1984-1986:296). One difference is that the affricate $g$ has a highly regular allophone (fricative) $\check{z}$ in HWA. In Barrāk transcription is with $\breve{g}$ throughout and is reported as "always realised as an alveolar affricate" (i.e. I.P.A. [d3]). ${ }^{68}$

A glottal stop often follows final stressed $-a$ in a pause (Barrāk:296): e.g. $\check{g} a^{3}$ "he came".

A similar situation in HwA, but 'is also often heard following unstressed final - $a$, e.g. áfda' "I sacrifice", tagádda' "he had lunch", biyrìdha' "he wants (i.e. loves) her" and ál 'aša "the dinner".

Such glottalization is not indicated in Barrāk.

Lack of affrication in reflexes of *k and *q in ḤwJ: same in Ḥ̂A.

Three short vowel phonemes: /i/, /u/ and /a/ in ḤwJ: same in ḤwA.

66 "Barrāk" for the poet Barrāk Dāgiiš Ğāziy Aḅuw Tāyih al-Ḥuwayṭiy recorded in Holes and Abu Athera 2009:83-108. Some of his poems appear there in transcription. He is from al-Ğafr in southern Jordan (see ibid.:8), some $150 \mathrm{~km}$ northeast of 'Aqabah.

${ }_{7}$ For the notation in transcription the interpretation of Said Salman Abu Athera was taken as a starting point for the texts, which were only available on paper (the poet himself had passed away in 1999). Said is himself a Bedouin of the Tarābīn, born in the Gaza area, and was raised in Jordan (Clive Holes, personal communication). Chances are therefore considerable that in Barrāk's transcribed poems Said's own Turbāniy or perhaps (partly) Jordanian dialect shines through.

${ }^{68}$ See Holes and Abu Athera 2009:210. 
Five long vowel phonemes: $/ \overline{\mathbf{l}} /, / \overline{\mathrm{u}} /$ and $/ \overline{\mathrm{a}} /$, and $/ \overline{\mathrm{e}} /\left({ }^{*}\right.$ ay) and $/ \overline{\mathbf{o}} /\left({ }^{*}\right.$ aw $)$ in HwJ: same in HwA. No real overlap (or fluctuation) of $/ \overline{\mathrm{e}} /$ with $/ \overline{\mathbf{i}} /$ or $/ \overline{\mathbf{o}} /$ with $/ \overline{\mathrm{u}} /$. In HwA very high $/ \overline{\mathrm{e}} /$ was heard in the lexical items $z \bar{e} t$, seef and $b \bar{e} t$, but such high realisations (near I.P.A. [ir]) of / $\overline{\mathrm{e}} /$ were the exception, rather than the rule.

Palva (ibid.) reports $/ \overline{\mathrm{e}} /$ and $/ \overline{\mathrm{o}} /$ in all positions in HwJ, including those preceded by velarized consonants or X. In HwA, however, diphthongs have remained in such positions, e.g, 'ayn "eye", xaymih "tent", nușșayn "two halves", șayf "summer", dawayt "I went home before sunset", hawlíy "one-eyed (sg. fem.)", gawțar "he went". The diphthong in 'ayš "bread" was often realised lengthened: 'ayš in HwA.

In Barrāk only a few diphthongs occur, e.g. hawl (p. 93, l. 5), aț-ṭbayg, (p. 96, 1. 37), taw in (p. 101, l. 4) but more regularly monophthongs are found following back spirants and velarized consonants, e.g.: hèel and xēel (p. 94, ll. 14 and 16) (but here perhaps to rhyme with sēl and mēl), hẹt (p. 95, l. 30), 'èn (p. 96, l. 43), țēr (p. 100, l. 29), ġèr (p. 100, 1. 32), bag்ètah (p. 101, l. 4) (here rhyming with nagètah and lagètah), șēf (p. 101, l. 5), a'tètah and na'étah (p. 102, ll. 20 and 21).

In terms of stress, the only diffence between HwJ and HwA appears to be that the former stresses $\mathrm{CáCaC}(\mathrm{v})$ (provided it is not $\mathrm{CaXaCv}),{ }^{69}$ while the latter clearly prefers stress $\mathrm{CaCáC}(\mathrm{v})$.

Examples for CaCaC from HwA are malág "hard soil/rock (i.e. where no foot prints will be visible)", libán "milk" and a gahawah-form dahár "back". HwA examples for CaCaCv are sibágah "race", zalámah "man", gaháwah "coffee”, hanákak "your mouth", afámak "your mouth”, tahárid ('ala) "you go up (to)", na'árif "we know".

In HwJ we see forms like (following numbers refer to pages in Palva 2004) ritam "retem (firewood)" (203) and siǧar "trees" (203) (stressed, according

\footnotetext{
69 This is how I interpret Palva's remarks, see 1984-1986:297. These remarks seem to be contradicted, however, by (verbal) forms listed on p. 299: $k(i) t a ́ b a t, k(i) t a ́ b o w /-u$ and $k$ (i)tábin. Although Palva $(2004: 197,198)$ repairs the error of listing the forms ga'dat, ga'dow/-u and ga'din by replacing them with the forms ga'adat, ga'adow/-u and ga'adin, we are now faced with a new question: why is *katab + at stressed $k(i) t a ́ b a t$, whereas ga'ad $+a t$ is stressed, I assume, gáa adat? This assumption is not without ground: the form ga dat could not have been listed if the proper form is ga'ádat, since I find it hard to believe that a stressed vowel would have been heard as having been elided. The error of listing the form ga'dat could therefore only be made because the proper form is gáadat.

When gahawah-forms are involved, we do find a CaCáCv stress-type, e.g. ba áda (Palva 2004:201).
} 
to Palva's remarks, ritam and siğar),${ }^{70}$ which prompt the question whether these are perhaps relics of an older CaCáC stress-type (in which the vowel $a$ of the first syllable in neutral environments is often raised > CiCáC). In other words: are we dealing with a stress shift in Hwētị, and is its older stress-type then more like the present situation in HwA of Sinai? (for further remarks, see 'the verb' below)

Apart from stress in sequences mentioned above, stress in both HwA and HwJ can be characterized by the forms: álbil "the camels", álwalad "the boy", ángalab/yingilib (imperfect in HwJ would be yángalib) "be overturned", áttafag/yittifig (imperfect in HiwJ would be yáttafig) "agree", bintī "my daughter", darabatni "she hit me". As for forms in Barrāk, no conclusions can be drawn with regard to stress.

As for the Nağdiy type of resyllabication of $\mathrm{CaCaCV}$ sequences (> CCICV, or (gahawah-sequences) CaXaCV $>\mathrm{CxaCV}$ ), it is not a feature of HwA. As for HwJ, however, there are several instances of forms that have been subject to this rule. Palva appears to report free variation with respect to the application of this rule. ${ }^{72}$ Notice the following forms in Palva 2004. (Following bracketed numbers refer to the pages, the form in square brackets would be the HwA equivalent, which are not affected by the Nağdiy resyllabication rule). First of all, gahawah-forms appearing in HwJ which are also resyllabified in conformity with the Nağdiy resyllabification rule are (forms listed in square brackets are proper HwA forms):

ghawah (1984-1986:303) [gaháwah], yǵazu "they raid" (201) [yaǵázuw], 3 instances of nxabiz "we bake" (202) [naxábiz], 3 instances of n'ağin "we knead" (202) [na'áǵin], 2 instances of ng்azil "we spin", nǵázila "we spin it" (203) [naǵázil and naǵázlah] and nḥașid "we harvest" (204) [naḥáșid].

${ }^{70}$ I have not listed $\mathrm{CaCaC}$ forms preceded by the (stressed) article. Other forms in HwJ without such raising are balad (204), hağar (204, 205, 206), masak (206), walad (206), 'ašar (207), sana (207), nasab (207) and hașal (208). Interestingly, in the paradigms for kitab and sirib (see Palva 1984-1986:299), $i$ of the first syllable may only be dropped when it is in open syllable directly preceding a stressed syllable (forms cited are e.g. $\check{s}(i)$ ríbti and $k(i)$ tábin). From this a conclusion that the second syllables in širib and kitab are not stressed logically follows, and therefore these forms must be stressed kitab and šírib (since $k t a ́ b$ and ‘šríb are not optional). For further implications, see remarks below in 'the verb'.

${ }^{71}$ For these imperfect forms of measures $n-1$ and $1-t$ in HwJ, see Palva 1984-1986:303.

${ }^{72}$ Listed verb forms with bracketed vowels, like $k(i)$ tabat and $y(a)^{\text {'arf }}$ (1984-1986:299), suggest free variation in the application of the Nağdi resyllabication rule and the forms yahkumu/ y hakmu (2004:207) also imply free variation in the application of the gahawahrule. For Nağdi resyllabification see Prochazka 1988:10-11 and Ingham 1986:276. 
But Palva also reports forms in HwJ which are not affected by Nağdiy resyllabification are: bacáḍa (2004:201), hasạalat (2004:205) šağara, šağarāt (2004:205), ga'adu (2004:205), haraka (2004:205), ḥağara (2004:206); darabat (2004:206), zalabāni (2004:206), yáhafru (2004:206), hafáraw (2004:206), hașalat (2004:207), sanawāt (2004:207, 208), 'ašara (2004:207), wahade (2004:207), 'agabe (2004:207, 208), madaniye (2004:207). Such forms are in terms of syllabication identical to comparable HwA forms.

In Barrāk instances of $\mathrm{CaCaCV}$ were not found.

gahawah-forms in Barrāk are: ar-ra'ad (p. 86, l. 11), wa l-wa'ad (p. 88, l. 4), and verb forms tahamdūh (p. 91, 1. 25), but there are also many forms which are not affected by the gahawah-syndrome (perhaps for metrical reasons), e.g. ša bah (p. 91, l. 27), ša b (p. 91, l. 28) and șa $b$ (p. 93, l. 8), an-naxlāt (p. 99, 1. 25) and verb forms yahfaḍōh (p. 91, 1. 20), yahkum (p. 91, 1. 28) and yax̌̌a (p. 95, 1. 23).

\section{Morphology}

Independent pronouns in HwA are aná, int $(a)$, intiy, hū, hī, ahnna, intuw, intin, huṃ(ma) and hin(na). For HwJ Palva reports ana, int, inti. hu, hi, ihna ( hinna), intu, intin, hum and hin. ${ }^{73}$

Also in Barrāk we find hiinna (p. 95, l. 31).

\section{Pronominal suffixes}

C-ī / V-y (poss.) and -nī (obj.), C-ak / V-k, -kiy, C-ah or C-ih / V-(h), -ha( $\left.{ }^{\circ}\right)$, $-k u w$ / -kin, $-n a\left(^{\prime}\right)$. In HwJ the same suffixes are current, except the allomorph $-i$ of the 3 rd p. sg. masc. ${ }^{74}$

In Barrāk we find singular forms like (3rd p. sg. masc. -ah or -ih) ša $b a h$ "his people" (p. 91, l. 27) and annās kullih "all people" (p. 85, l. 3) and (v + -h) yi țūh "they give him" (p. 89, l. 22); (3rd p. sg. fem. -ha) gașdha "her intent" or a long vowel at the end of a hemistich as in warāha "behind her" (p. 86, l. 7); (2nd p. sg. masc. -ak) ğěšak "your army" (p. 86, l. 6) or (v + -k) as in malfāk "your destination" (p. 93, l. 6); a short final vowel in (1st p. sg. com. -i) rizgi "my sustenance" (p. 101, l. 9), (v + -y) mabdāy "my principle" (p. 101, l. 6) and (obj. suff. -ni) talabni "he asked me" (p. 98, 1. 5). Plural

\footnotetext{
73 See Palva 1984-1986:297 and 2004:198. Palva also mentions that in pause, ana, $h \bar{u}$ and $h \bar{\iota}$ sometimes have an audible glottal stop following. In HwA I have only noticed this in the case of ana $^{\prime}$ \#, but then not only in pause.

${ }^{74}$ I follow a slightly different system of transcription in forms like -kuw and -kiy (Palva writes $-k u$ and $-k i$ ). I have not recorded (unstressed and short) $-i$ or $-n i$ for the 1st p. com. sg. in HwA, which Palva 1984-1986:197 gives for HwJ.
} 
forms are (3rd p. pl. masc.) ahalhum "their people" (p. 100, l. 33); (3rd p. pl. fem. -hin) la buddhin "they must"; (2nd p. pl. masc. -kum; -ku(w) was not recorded) ğihädkum "your fight" (p. 86, 1. 15); the 2nd p. pl. fem. was not found; (1st p. pl. com. -na) baladna "our land" (p. 89, l. 17).

Demonstrative pronouns in HwA are

Near deixis: hāda, hādiy ( fewer hēdiy), hadál (-lah),

Far deixis: hadāk, hadīk (-ih) ( fewer hēdīk (-ih)), hadallāk(-ah)

In $\mathrm{HwJ}$ the same forms were recorded. ${ }^{75}$

A feature considered very typical of HwA by other tribes is the postpositioned demonstrative ha, e.g. álwalad ha... "this boy". This feature was not reported for HwJ, nor were instances found in Barrāk.

\section{Interrogatives}

min is used for "who?" in both HwA and HwJ. ${ }^{76}$

For the interrogative "what?" $\bar{e} h$, much less regularly $\bar{e} s$ and sometimes wiš were heard in HwA. For HwJ Palva ${ }^{77}$ gives wuš, co-occurring with $\bar{e} \check{s}$ and K-form $\check{s} \bar{u}$ (with proclitic variants 'iš and $\check{s} u$ ).

"Which" is yāt in HwA, but ayy / ayya in HwJ..$^{8}$

The b-imperfect

For HwJ Palva reports that the $b$-imperfect is not current in HwJ. ${ }^{79}$ Barrāk shows no instances of the $b$-imperfect either. In HwA, however, it is as current as in other dialects of Sinai (except in that of the Dawāgrah).

Indefinite pronouns and the article ${ }^{80}$

HwJ wāhad-HwA wāhid "someone", both variants have šiy "something", kam "some", "all, every, whole" is kill in HwJ—kull in HwA, the article is alin both variants, and also often ('konkretisierendes') ${ }^{8_{1}}$ hal-. ${ }^{8_{2}}$ The relative pronoun is alli(y) in both, while halli is also reported for HwJ (the latter was not heard in HwA).

75 See Palva 1984-1986:298 and 2004:198.

${ }^{76}$ See Palva 1984-1986:298.

77 See Palva 1984-1986:298 and 2004:198.

${ }^{8}$ See Palva 1984-1986:298

${ }^{79}$ See Palva 1984-1986:307 and 2004:196

${ }^{80}$ For remarks on HwJ, see Palva 1984-1986:298

${ }^{81}$ See Blau 1960:20 and Grotzfeld 1964:46-47.

${ }^{82}$ For postpositioned ha in HwA, see remark in III, 3.1.9.1. 


\section{The verb in $H w A$ and $H w J$}

Perfect verb forms listed for $\mathrm{HwJ}$ reflect the $a$-type as $\mathrm{CiCaC}$ or $\mathrm{CaCaC}(<$ $\left.{ }^{*} \mathrm{CaCaC}\right)$ and the $i$-type as $\mathrm{CiCiC}$ or $\mathrm{CaCiC}\left(<{ }^{*} \mathrm{CaCiC}\right)$. Palva ${ }^{83}$ concludes that the vowel of the first syllable in both types depends on the phonetic surroundings. To summerize his point: if $a$ of the first syllable in ${ }^{*} \mathrm{CaCaC}$ was realized with a back allophone, it has remained $a$ (e.g. ga'ad), but if it was realized with a front allophone, it has become $i$ (e.g. kitab). In the older $i$-type $\left({ }^{*} \mathrm{CaCiC}\right)$ the same development is concluded, but an additional factor of vowel harmony is held responsible for this change. Examples cited are 'arif $\left(<{ }^{*} \mathrm{CaCiC}\right.$, in which $a$ is concluded to have been realized with a back allophone) and širib $\left(<{ }^{*} \mathrm{CaCiC}\right.$, where $a$ is concluded to have been realized with a front allophone).

Apart from the fact that it is difficult to imagine a back allophone for $a$ in 'arif (which would then have to be more or less like (the vowel in the first syllable) $a$ in e.g. darab, i.e. near I.P.A. [a]), ${ }^{84}$ there is a more plausible explanation.

A historically more plausible development to account for raising $a$ $>i$ in these patterns is to postulate a stress shift from $\mathrm{CvCv́C}$ to $\mathrm{Cv} \mathrm{CvC}$ (see also Grotzfeld 1969); patterns that are now stressed on the first syllable must have been stressed on the second syllable to allow the vowel $a$ in neutral surroundings to be raised to $i$. The scenario in which raising of short vowel $a>i$ in open syllable preceding a stressed syllable takes place is not unique in the area (see paragraphs 1.2.3.4.3.2. and 3.1.1.6. of preceding descriptive chapters), nor is stress of the CaCáC- or CiCíC-type (see paragraphs 2.1.1.2.1. of preceding descriptive chapters; HwA also has CaCáC and CiCíC, e.g. kitáb and širíb).

The implication is that Palva's suggestion of raising of $a$ in ${ }^{*} \mathrm{CaCiC}(>$ $\mathrm{CiCiC}$ ) in $\mathrm{HwJ}$ as the result of vowel harmony ${ }^{85}$ appears to be off the mark. After all, why would $a$ in ${ }^{*} \mathrm{CaCaC}$ be raised $(>\mathrm{CiCaC}$ ) if a mechanism of vowel harmony were operative ${ }^{86}$

$8_{3}$ See Palva 1984-1986:298-299.

${ }^{84}$ In fact, preceding ' or $h$ more typically result in an open front allophone near I.P.A. [a].

${ }_{5}$ As was assumed in Palva 1984-1986:298.

${ }^{86}$ Palva ibid. recognizes this, but does not elaborate. Also the fact that the vowel of the imperfect preformative does not harmonize with the stem vowel is an indication that vowel harmony (present in almost all dialects of Sinai, including HwA) is at least not a very productive rule in HwJ (see ibid.:299-301). Some examples of such lack of vowel harmony cited for HwJ are yag'ud, yaktib, yamši, yadri, etc. 
The more likely historical development is that after such raising ( $a$ $>i$ ) in neutral surroundings had become stable, resulting in CiCáC and CiCíC, ${ }^{87}$ stress shifted onto the first syllable, resulting in the forms that were recorded (e.g. kítab and širib).

The question remains then, why did stress shift? There is no easy answer, but chances are that HwJ has been influenced by a dialect-type which stresses Cv́CvC. The dialect-type could be a sedentary (rural or urban) type in southern Jordan, or perhaps even contact with speakers of a Nağdiy (i.e. a Bedouin type, but non-NWA) type of dialect; after all, the very same vowelling and stress-type are current in Nağdiy (e.g. the active (a-type) perfect forms kitab "he wrote", díbah "he slaughtered", but-due to lowering influences of contiguous $h$ and '-no raising in e.g. ( $a$-type perfect) hálab "he milked" and gá ad "he sat" ${ }^{88}$ and also (i-type perfect) "ášiǵ "he loved" $\left.{ }^{89}\right) .^{90}$

The confusing differences in stressing in forms like gá adat, but $k(i)$ tábat and (gahawah-forms) $y(a)^{\prime}$ 'árf and gháwah are already an indication that dialect contact may be have taken place (or is still operative); two systems for stressing sequences of the type $\mathrm{CaCaCv}(\mathrm{C})$ appear to be in use and exist side by side as parallel systems. And parallel forms, or parallel systems in this case, are often an indication of dialect contact. ${ }^{91}$

In any case, the topic of stress shift deserves more attention than it can receive here.

Like in HwA, $a$ of the $i$-type perfect (underlying $|\mathrm{CaCiC}|$ ) in HwJ 'reappears' in closed syllables, e.g. šarbin "they (fem.) drank". A difference is the vowel of the 3 rd p. sg. fem. ending: šarbit in HwA, but šarbat in HwJ. ${ }^{92}$

${ }^{87}$ Such forms are not exceptional in the area, see map 14 in the appendix.

${ }^{88}$ See Prochazka 1988:28-29.

89 See ibid.:32.

90 If we look at stress systems current in some Nağdiy dialects (see Prochazka 1988:20-22), we see that there too a stress shift may have been involved in shaping forms that are heard today. If we take forms like (active) *katab "he wrote" and (internal passive) * kItib (in which $I=i$ or $u$ ) "it was written" as starting points, and we assume that both forms were stressed on the ultimate (katáb and kItíb), postulating stress on the ultimate syllable would not only account for raising of $a$ in katáb > kitáb, but also for the elision of the short high vowel $I$ from the open (first) syllable in $k I t i b>k t i b$. When stress then shifted, it could only do so in the active form (resulting in kitab, cf. ibid.:28), but stress could no longer shift in the internal passive form, since the vowel of the first syllable was no longer available after its elision, and stress had to remain where it was: ktíb (cf. ibid.:116). On stress shift in Arabic dialects, see also Grotzfeld 1969 .

${ }^{91}$ See Trudgill 1986:107-108 on the dynamics of dialect contact.

${ }^{2}$ See Palva 1984-1986:299. 
The vowel of in the 3 rd p. pl. fem. perfect ending in HwA colours with the base vowel: -an in the $a$-type perfect (e.g. katában) and -in in the $i$-type perfect (e.g. šarbin). In HwJ the situation is not clear, but Palvawith some hesitation-lists the forms with a fixed $i$ in this morpheme ( $k(i)$ tábin and šarbin $) \cdot{ }^{93}$

Similar hesitation is apparent in the endings listed for the $3^{\text {rd }} \mathrm{p}$. pl. masc., for which Palva lists -ow/-u for both vowel-types of the perfect in HwJ (k(i)tábow/-u and šarbow/-u). In HwA vowel harmony produces -aw in the $a$-type (katábaw or kitábaw). The ending in the $i$-type (and also in the $u$-type) is $-u w$ (šarbuw).

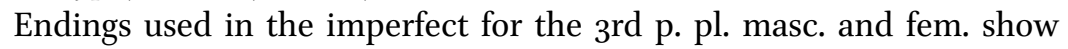
the same differences. Examples for the fem. are byaṭanan iw biygáriblin "they (fem.) grind and sieve" in HwA, but in HwJ tákitbin / taktibin and tašrabin. Examples for the masc. are yíkitbuw and yašrabaw in HwA, but in HwJ forms are yákitbu / yaktibu and yašrabu, and fem. pl. forms are yákitbin / yaktibin and yašrabin. ${ }^{94}$

Barrāk lists some forms with the (more Nağdiy-like) pl. masc. ending -ūn, e.g. yišfün (p. 86, l. 6) and yirmūn (p. 86, l. 7), but there can be little doubt that this is due to the high register chosen for this poem. ${ }^{95}$ Other forms in Barrāk more strongly suggest a situation like in HwA, e.g. (perfect) iḥtāğaw (p. 95, 1. 21) and (imperfect) yaḍakaw (p. 91, 1. 21) and there are many instances where suffixation results in monophthongized -aw or $-o w>-\bar{o}$, as in (perfect) sawwōh (p. 90, 1. 2) and (imperfect) yahfadōh (p. 91, 1. 20), while suffixation of $-u w$ results in $-\bar{u}$, as in (perfect) and (imperfect) ysammūh (p. 90, l. 1) and tahamdūh (p. 91, l. 25).

In poetry (Barrāk, pp. 93-97) many instances may be found of vowel harmony in the pl. fem. endings of perfect and imperfect: -an for the $a$-types and -in for the $i$-types, e.g. (perfect) bayyananni (p. 95, 1. 22) and imperfect (a-type) yarhalanni (p. 94, l. 18) and (i-type) yihtifinni (p. 94, l. 11). ${ }^{6}$

In HwA the vowel of the imperfect preformative colours with the stem vowel through vowel harmony, e.g. yiktib, yudrub and yarğa', while in HọJ

\footnotetext{
93 See Palva 1984-1986:299.

94 Ibid.:299-300.

95 The poem was actually recited by the poet to king Husayn of Jordan, see ibid.:84-85.

${ }^{96}$ Endings there are actually -anni and -inni, instead of -an and -in; the additional -ni being a poetic device.
} 
the preformative is with fixed $a$, e.g. yaktib, yadrub and yarğa ${ }^{c}{ }^{97}$ In Barrāk the system is basically like in HwA, e.g. yisfik (p. 86, l. 10), yihyi (p. 89, l. 25), yimši (p. 88, l. 8), yibnūh (p. 9o, l. 4), tunkus (p. 89, l. 15), yund̆ur (p. 89, l. 26), yudkur (p. 10o, l. 34), tunșur (p. 91, ll. 15, 16), yuțlub (p. 91, 1. 23), nudukrah (p. 101, l. 9), yurzug (p. 101, l. 9) and also yasrax (p. 86, l. 14) and tarkab (p. 94, ll. 16, 17), but also (exceptions) ya izzhum (p. 89, l. 26) and tafrig (p. 96, l. 43).

Imperatives in HwA have initial vowels coloured by vowel harmony: ug $u d$, iktib and ašrab. In HwJ such colouring is absent from the $a$-type: ug'ud, iktib, but išrab. ${ }^{98}$

\section{Some weak verbs}

Primae wāw verbs in Ḥ̂A have incorporated wāw in the preformative, often monophthongal $\bar{o}$ in the $i$-type, as in yōrid, and diphthongal $a w$ in the $a$-type, as in yawșal. For some verbs another paradigm without incorporated wāw is also available, as in yigíf and yiríd.

In $H w J$ the preformative contains long $\bar{a}$, as in yāgaf and yāsal. A shorter form la tiga ' was also recorded in H. ${ }^{1}{ }^{99}{ }^{99}$ Barrāk gives a form yāgafanni (for the -ni ending, see remark above) (p. 96, l. 33).

In tertiae yâa $a$-type imperfects in HwA the base vowel is not dropped when vowel-initial endings are appended, e.g. tansay, yansaw. In HwJ however the base vowel is dropped, e.g. tansi, yansu. ${ }^{100}$ In Barrāk we find forms like in ḤwA:yardaw (p. 88, 1. 10) and yitnāsōh (suffixed -aw or -ow $>-\bar{o})$ (p. 9o, l. 9).

The imperfect vowel in the primae hamzah verbs is $i$ in HwA, HwJ and Barrāk: yākil (p. 99, l. 25) and yāxid (p. 88, l. 11; p. 96, l. 39).

The perfect forms are with initial $a$ - in both HwwA and Ḥw: akal, akalt, etc.

The verb "come"

In forms in HwA the vowel of consonant-initial imperfect preformatives has been dropped (and the final syllable is stressed): yğiy, tğiy, nğiy, tğuw,

\footnotetext{
97 See Palva 1984-1986:299-301.

$9^{8}$ Ibid.:300.

99 Ibid.

100 Ibid.:301
} 
tğin, yğuw and yğin, but (1st p. com. sg.) ağíy. In Ḥw the vowel has not been dropped and is stressed (leaving the ending unstressed): yígi tíği, etc.

Derived measures

In perfect and imperfect of measures $t a-2$ and $t a-3$, the $t a$-prefix is only rarely reduced to (i)t- in HwA. Examples are tagadda, ytagadda and tasālam, ytasālam.

In HwJ reduction of $t a$ or $t a>t$ in the imperfect (but not in the perfect)

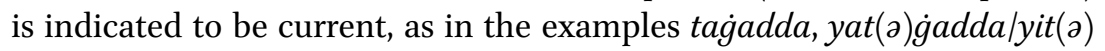
gadda and tasālam, yat(ə)sālam/ yit(ə)sālam. ${ }^{101}$ In Barrāk we find forms like iytarağğāh (p. 91, 1. 13), tabāšaraw (p. 91, 1. 21), tasallam (p. 98, 1. 8).

In measures $n$-1 and 1- $t$ the first syllable in the perfect and imperfect is stressable in HwA and HwJ, but vowelling in the imperfect differs. Examples are ánfatah, yínfitị and ástawa, yístiwiy in ḤA, but ánfataḥ, yánfatị̣ and ástawa, yástawi in HwJ..$^{102}$ In Barrāk we find forms like ida nkasar (perhaps stressed id-ánkasar) (p. 88, 1. 15), but also infağar (p. 91, 1. 22), ingalab (p. 95, 1. 27) yihtașilhā (with $a$ in the stem, but not in the preformative) (p. 89, 1. 21), yimtațilhä (ibid.) (p. 89, 1. 21), yihtifinni ${ }^{103}$ (p. 94, 1. 11).

\section{Nominal morphology}

The degree of raising of the fem. morpheme differs slightly: in HwA up to $\left[\mathrm{l}^{\mathrm{h}}\right]$ in neutral surroundings, but in HwJ mostly $[\varepsilon] .^{104}$ In Barrāk we see many examples where final $-i h$ is transcribed, e.g. the poem on pp. 98-100.

\section{Tanwin}

Tanwin is not a feature of HwA or HwJ, but in Barrāk's poems quite a number of instances of are found. The use of tanwīn (i.e. appending final -in) is however restricted to poetry and sayings and the like and is not current in every day speech.

\footnotetext{
${ }^{101}$ See Palva 1984-1986:302-303.

102 Ibid.:303.

${ }_{103}$ The final syllable is a poetic device; the poem rhymes in -ni.

104 See Palva 1984-1986:303.
} 


\section{Particles}

Some differences between adverbs in HwA and $\mathrm{HwJ}^{105}$ are:

\begin{tabular}{|c|c|c|}
\hline Hwa & HwJ & \\
\hline hniy(yih) & $\dot{h a ̄ n}$ & "here" \\
\hline hnuh & hināk & "there" \\
\hline kidíy(yih) & $h \bar{e} k$ & "thus, this way" \\
\hline lēh & $l \bar{e} s$ & "why?" \\
\hline mata & matān/mitān, wagtēh & “when?" \\
\hline kam & kam/kutrayh & "how many?" \\
\hline gaddēh & gaddēěs & "how much?" \\
\hline dāyman & daym & "always" \\
\hline 'a(la) țūl & duǵri & "straight" \\
\hline
\end{tabular}

Some differences in conjunctions

yōm is current for "when" in HwA and HwJ, but nhār was not recorded in HwA in the same meaning.

inkān is current for "if" in HwA and HwJ (and also Barrāk, e.g. p. 103, ll. 25 and 29), but (')ila was not recorded in HwA for "if" (but instances in Barrāk are, e.g., on p. 103, ll. 22 and 28), nor was suffixed kann- or kānn-. In Barrāk an instance of suffixed kann is kannak tidakkar "if you remember" (p. 102, 1. 15). ${ }^{106}$

For "until" lamma is current in both HwA and HwJ, but lamman and yāma were not recorded for "when" in HwA.

lākin and mār are used for "but, but then" in HọJ, but only bass was heard in HwA for "but".

Some differences in (suffixed) prepositions

Prepositions $m a$ " "with" and $l$ "to" suffixed with the 1st p. sg. com. pronominal are ma'áy and lay in HwA. In HwJ forms are ma' $i$ and $l i$.

The shorter form ' $a$ for 'ala "on" may in HwA also be used in positions not directly followed by the article, e.g. 'a ğâl "aside" and 'a dahár álǧimal "on the back of the camel". In HwJ ' $a$ is only used when the article directly follows. ${ }^{107}$

mițl for "as, like" is used in HwJ, but in HwA zayy is current. miț also appears in Barrāk (p. 86, l. 11).

${ }^{105}$ Ibid.:304-305.

${ }^{106}$ A footnote explains tidakkar < titdakkar, but reduction of the initial geminate $t t$ as in ttidakkar is very well possible, see remark in fn 8o, p. 176 .

${ }^{107}$ See Palva 1984-1986:306. 
Differences between some irregular high-frequency nouns

Similarities in HwA and HwJ are for "father" (') $a b \underline{b}$ and (') $a b \bar{u}$ - in construct state; for "mother" (')ammm; for "brother" (') $a x x$ and (') $a x \bar{u}$ - in construct state. A difference is (')uxt in HwA, but (')axt in HwJ.

In HwA the pl. for "hand" ((')ìd) is (')ìdàn, in HwJ it is (')adèn. "Hands" suffixed in HwA is $\bar{\imath} d \bar{a} n$ - (e.g. $\bar{\imath} d \bar{a} n \bar{\imath}$ "my hands"), but in HọJ it is (')adé(e.g. (')adēk "your hands").

A similarity is (')afám for "mouth", e.g. (')afamī "my mouth" and (')afámak "your mouth".

A difference is "water": (')álma (with incorporated article!) in HwJ, but miy in HwA.

\section{The analytical genitive}

The analytical genitive is not frequent in HwJ. In HwA the analytical genitive with šuğ is current. I have not come across instances in Barrāk.

\section{Negated pronominals}

In Ḥ̂A $m \bar{u} h \bar{u} \sim m \bar{a} h \bar{u}$ and $m \bar{\imath} h \bar{\imath}$ in Ḥ̂, HọJ has $m \bar{u} \sim m u h u$ and $m \bar{\imath} \sim$ $m i h i^{108}$ and in Barrāk we find ma hu (p. 98, l. 3) and ma hi (p. 89, 1. 22).

The comparison above shows that between these different branches of the same tribe (or tribal confederation) there are already many differences. The differences found-if there ever was a common starting point - must have arisen not only as a result of dialect contact with other tribes (or they are perhaps 'internally motivated'), but the development of differences may also have been facilitated by the very lack of contact between the different branches due to their geographical separation over a longer period of time ${ }^{109}$ (the Hwêțāt of Sinai are estimated to have arrived there in the $17^{\text {th }}$ century at the latest, see Introduction, I. c.); as the crow flies the distance between the dīrahs of the Hwẹtat of Sinai and southern Jordan is approximately $200 \mathrm{~km}$. Apart from that, regular contact between the two branches must have been severely hampered by the presence of new borders that came with the creation of the state of Israel in 1948.

Of the two varieties HwA is clearly of the group I type found in Sinai and the Negev (see also MDS plots and dendrogram in the appendix), while HwJ shows characteristics that are best attributed to contact with dialects which are more of the Nağdiy-type (see also remarks made in Palva 2008b:406).

\footnotetext{
108 Ibid. 307 .

${ }^{109}$ Due to the lack of contact, changes that appear in one variety cannot (any longer) be 'corrected' by speakers in another location of originally the same dialect.
} 


\section{Final Conclusions}

\section{a. The Position of Sinai Dialects in Northwest Arabian Arabic}

(the NWA-group)

The larger typological dialect group of Northwest Arabian dialects of Arabic (as was proposed in Palva 1991) was shown in De Jong 2000 to be present in northern Sinai (groups I, II and III), along the Mediterranean coast.

When we now check features of groups VI, VII and VIII against features listed as characteristic for NWA dialects in Palva 1991:154-165, we notice the following (only dialects of groups VI, VII and VIII are discussed here $\left.^{110}\right):{ }^{111}$

i Absence of tanwin and its residues: groups VI, VII and VIII conform (cf. 4.1.).

ii Absence of affricated variants of $/ \mathrm{g} /\left({ }^{*} \mathrm{q}\right)$ and $/ \mathrm{k} /\left({ }^{*} \mathrm{k}\right)$ : groups VI, VII and VIII conform (cf. 1.1.1., 1.1.3.).

iii Absence of final /n/ in the imperfect, 2nd p. sg. fem., 2nd p. pl. masc. and 3 rd p. pl. masc.: groups VI, VII and VIII conform (cf. 3.2.1.2.).

iv Pronominal suffix $-k u$ (-kuw in my own transcription) in the 2nd p. pl. masc.: groups VI, VII and VIII conform ( - -kum in VII and VIII) (cf. 3.1.12.2.).

$\mathrm{v}$ Use of locative preposition $f i$ : groups VI, VII and VIII conform (cf. 3.1.16.).

vi Interrogative $k \bar{e} f$ : groups VI, VII and VIII conform (cf. 3.1.14.).

vii Voiced reflex of $q \bar{a} f$ : groups VI, VII and VIII conform (cf. 1.1.1., 1.1.3.).

viii The gahawah-syndrome and the CVCaCV- > CCVCV- syllable structure: ${ }^{12}$ groups VI, VII and VIII conform (cf. 2.2.1.1., 2.1.1.2.1.6. in De Jong 2000 and 2.1.1.2.2. in the vol. in hand).

${ }^{10}$ Since dialects of group I discussed in this volume are grouped together with other group I dialects described in De Jong 2000, whose NWA status has already been established there, the same NWA status of the group I dialects discussed in the volume in hand logically follows.

${ }^{111}$ The features are cited here as they were listed in Palva 1991. In a number of instances additional data have become available and appeared in De Jong 2000. The reader is referred to relevant paragraphs by the numbers following in brackets.

${ }^{112}$ This was rephrased as two separate criteria in De Jong 2000:48-50. The conclusion there was that resyllabication of $\mathrm{CaCaCV}$ sequences (> CCVCV) is not a feature of NWA 
ix Gender distinction in the end and $3 \mathrm{rd} \mathrm{p}$. pl. in personal pronouns, pronominal suffixes and finite verb forms: groups VI, VII and VIII conform (cf. 3.1.12.1., 3.1.12.2., 3.2.1.1., 3.2.1.2.).

$\mathrm{x}$ The definite article (')al- and the relative pronoun (')alli/halli: groups VI, VII and VIII conform only in part: al- il- and alliy illiy (cf. 3.1.9.1.).

xi A number of typical Bedouin lexical items (gōtar, sōlaf, țabb etc.): groups VI, VII and VIII conform (cf., e.g., 3.2.3.9.).

xii Occurrence of stressed variants $-\bar{\iota}$ and $-n \bar{\iota}$ of the pronominal suffix in 1st p. sg. com.: groups VI, VII and VIII conform (cf. 3.1.12.2.)

xiii Occurrence of $/ \mathrm{a} /$ in the initial syllable in verbal forms VII-X in the perfect, and the stability of this vowel, shown by stress on the initial syllable when in stressable position: group VI conforms, groups VII and VIII do not conform (cf. 3.2.3.1., 3.2.3.3., 3.2.3.4.).

xiv Occurrence of $/ \mathrm{a} /$ in the initial syllable in a number of irregular nouns ('amm, 'axt, 'axwān, 'adēn, 'afám): MzA of group VI and ĞbA of group VII conform in part. Other dialects do not conform (cf. 3.1.9.2.).

$\mathrm{xv}$ The invariable pronominal suffix - $k i$ of the 2 nd p. sg. fem.: groups VI, VII and VIII do not conform (cf. 3.1.12.2.).

On characteristics listed in Palva 1991, which are not shared by all NWA dialects, the following remarks are to be added:

xvi The use of $b$-imperfect: present in groups VI, VII and VIII (cf. 4.3.).

xvii Vowel harmony in the active imperfect of verbal form I: groups VI, VII and VIII conform (cf. 3.2.1.2.).

xviii Well-established monophthongs $/ \overline{\mathrm{o}} /$ and $/ \overline{\mathrm{e}} /$ vs. partial monophthongization of the older diphthongs, and $/ \overline{\mathrm{o}} / \sim / \overline{\mathrm{u}} /, / \overline{\mathrm{e}} / \sim / \overline{\mathrm{i}} /$ fluctuation: in group VI older diphthongs remain in certain environments, in groups VII and VIII monophthongization is not phonetically conditioned (cf. 1.2.4.).

xix The phonetically conditioned sg. fem. status absolotus marker allomorphs /-a/ and /-i/ in Sinai and the Negev, vs. a less strong 'imäla in the front allomorph in the dialects of the Hwēețāt and Baniy 'Ațiye

dialects, whereas sequences of the type $\operatorname{CICV}(\mathrm{C})$ (where $\mathrm{I}=i$ or $u$ ) have as a rule been resyllabified in NWA dialects, e.g. *'inab > 'nab "grapes", *turā $b>\operatorname{tra} a \bar{b}$ "dust". 
(/-a/ and /-e/): group VI has [ $\left.\mathrm{I}^{\mathrm{h}}\right]$ in neutral enivironments, groups VII and VIII tend to have slightly lower 'imälah, between $\left[\mathrm{e}^{\mathrm{h}}\right]$ and $\left[\mathrm{l}^{\mathrm{h}}\right]$ (cf. 1.2.3.4.3.3.).

$\mathrm{xx}$ The pronominal suffixes of the 3 rd p. sg. masc. C-ih, fem. -hiy in the Negev, masc. C-ah, fem. -ha in Sinai, the Hiwēțât and Bani 'Ațìye, masc. $-a h /-i h$, fem. -ha the Bdūl, masc. C-o, fem. -ha the N'ēmāt; groups VI, VII and VIII have masc. -uh and fem. -hal-hi(') (cf. 3.1.12.2.).

xxi Occurrence of several different plural forms of the demonstrative pronoun: most dialects in groups VI, VII and VIII show doubling of the $l$ (or !) in the pl. com. demonstrative, e.g. (hā) dill(-ih), dillēlih"13 (cf. 3.1.13.).

In addition to these features discussed with regard to NWA dialects in Palva 1991, it is important to note that all dialects of groups VI, VII and VIII (as well as southern dialects of group I) are 'différentiels' in terms of elision of short vowels; short high vowels $i$ and $u$ are dropped in eligible positions, while (underlying) short low vowel $a$ is not elided in comparable positions, e.g. širib (|šarib|) + -it > širbit, šarbit or šarbat, but katab + -at > kátabat or katábat kitábat (i.e. not •katbat).

Notwithstanding some differences between the dialects spoken in the central and southern regions of Sinai, there can be little doubt that these dialects are indeed a continuation of the NWA-group. There are some features of the southern Sinai dialects, however, that do not conform to the more typically NWA-type. The hypothesis of the presence of NWA Bedouin dialects throughout Sinai (with the exception of the dialect of the Dawāgirah and that of the town of al-'Arīšs, see De Jong chapters IV and V) is nevertheless corroborated.

At the same time the conclusion to be drawn with regard to the question how far the Negev-type stretches into Sinai is that this type is represented by the group I dialects identified, which then border on the southern dialects of groups VI, VII and VIII. For a large part the escarpment of the Tîh plateau is the geophysical obstacle where isoglosses accumulate to form the border between the Negev-type and the southern Sinai-type.

\footnotetext{
${ }^{13}$ This is characterized as "one of the most important peculiarities of the whole NWA group" (cf. Palva 1991:165). Some of the group I dialects (like TAS and TAN) may have forms without doubling for near deixis (e.g. $h \bar{a} d \bar{c} l, h \bar{a} d a l$ or $h \bar{o} d a l)$ as current for near deixis, but all have doubling in forms for forms used for far deixis (e.g. hōdallāk(-ah) or hä dolḷăk(-ah)).
} 
An earlier hypothesis of the presence of a transitional area in Jordan, where a number of dialect characteristics reported for the Hwētāt and Bani 'Ațiyye (see Palva 1984-86) suggest influences from non-NWA dialects, was contradicted by Palva. The hypothesis was for the presence of a transition area between NWA and a more Nağdi-type of dialect(s) (see also the discussion above in Conclusions, V.). ${ }^{114}$

The question of whether or not dialects are "différentiels" or "nondifférentiels" — with NWA dialects being "différentiels" — was not the only indication that the dialects of the Hwēțāt and Bani 'Ațiyye have had influences from non-NWA (possibly Nağdi) type of dialects. ${ }^{115}$

Another important indication was the Nağdi-type of resyllabication $(\mathrm{CaCaCV}>\mathrm{CCvCV})$, that seems to be current in the dialects of the Bani 'Ațiyye and Hwēțāt in Jordan. ${ }^{116}$

In addition, it should be noted that the Hwẹtạat are much more a relatively recent amalgam of social entities of different backgrounds ${ }^{117}$ than other tribes - such as most tribes in Sinai-who usually have a more homogeneous background, at least in relatively recent history. Chances that (again, relatively) recent additions to this collective known as 'the Hwēțāt' have until today preserved some of the features of their original dialects should not be excluded; it may also account for some of the contradictory findings reported for Jordanian 'Hwệțiy' in the available literature. Clearly, more research into the dialect situation in southern Jordan and its surroundings is needed to untangle this (seemingly?) contradictory information.

${ }^{114}$ Palva 2008b:407 erroneously quotes the conclusion in De Jong 2000:630 as (quoting from Palva 2008b) "[that] the existence of such a group [i.e. NWA] is questionable and deserves reconsideration". The passage referred to in De Jong 2000 actually reads: "Palva's conclusion that Hwētiy is part of his proposed NWA group deserves [therefore] reconsideration". In other words: the position of the dialects of the Hwẹtāāt and Bani 'Ațiyye as NWA-type of dialects deserved such reconsideration; the presence of an NWA-group is nowhere questioned in De Jong 2000, nor is it questioned here.

${ }^{115}$ Interestingly, at-Tayyib 1993:222 relates stories told by older tribesmen of the Bani 'Ațiyye of their origin in the eastern Nağd, from where they (then still known as Ma'āzah) migrated westward in the beginning of the fifth century Hiğrah (beginning of the eleventh century CE) to Taymä, after which they continued farther westward two centuries later (i.e. the beginning of the thirteenth century CE) to arrive near Tabūk (in present day Saudi Arabia, some 180 kilometres southeast of 'Aqabah). The Ma'āzah-or part of this collective-are today found in the eastern desert of Egypt (see map on p. 4 or p. 372).

${ }_{116}$ These and a number of other differences between Hwētiy as described by Palva and the Negev-type are listed in De Jong 2000:627-630.

${ }_{117}$ See remark ${ }^{* 11}$ in Introduction, I, d. 
Another answer to one of our earlier research questions is that the vowelless pronominal suffixes ${ }^{-}{ }^{u} k$ for the 2 nd p. sg. masc. and $-k$ for the sg. fem. are indeed a characteristic feature of the dialects spoken in the south of Sinai; these pron. suffixes are in regular use in groups VI, VII and VIII. The remark of the older speaker of the Samänah in the north, that his tribe had until the turn of the century (i.e. around $1900 \mathrm{CE}$ ) had their home in the region of at-Tür, may very well be true. If we combine the presence of the ${ }^{-}{ }^{u} k$ suffix in his speech $(\mathrm{SaA})$ with the presence of the pronominal suffix -kum $(\sim-k u w),{ }^{118}$ and also the verbal suffixes ending in - $m$ of the 2nd and 3 rd p. pl. masc. in the perfect and imperfect, ${ }^{119}$ and see that the combination of these characteristics is also found in 'LA and HmA, his remark acquires special significance. If linguistic evidence is anything to go by for conclusions on geographical origins of speakers, one would conclude that the Samānnah (and perhaps also the 'Agāylah) must have had their earlier abode in the region north of the lower end (not too far from the Gulf of Suez) of Wādiy Fērāan (i.e. the area around Wādiy Garandal and Wādiy Lihyān). Unfortunately, I could not find other indications that would support this conclusion.

Apart from the necessity of more research into the hypothesized border area between the NWA- and Nağdiy-groups of dialects, a remaining desideratum is a systematic survey of the dialects of the Hiğāa to establish how far-if at all - the North West Arabian dialect group reaches south along the Red Sea coast of western Saudi Arabia.

In the eastern desert of Egypt the dialect of the Ma âzah (which is hypothesized here to be part of the NWA group) borders on the dialect of the 'Abābdah (which can be seen as the northern extension of the Sudanese type of Arabic dialects, ${ }^{120}$ like that of the Šukriyyah ${ }^{121}$ ). Research into the dialect of the Ma āzah is needed to establish whether it is indeed the southwestern extremity of the NWA group on the Egyptian mainland. ${ }^{122}$

\footnotetext{
${ }^{118}$ See De Jong 2000:283-288.

${ }^{119}$ See De Jong 2000:298-299.

${ }^{120}$ As described in De Jong 2002, and see remarks in Woidich and Behnstedt 1980:176 (fn 1 ).

${ }^{121}$ As described in Reichmuth 1983 .

${ }^{122}$ Although Hobbs 1989 is an excellent anthropological study on the Ma āzah, the transcription used there for Arabic is less suitable for linguistic interpretation of the features of their dialect.
} 